
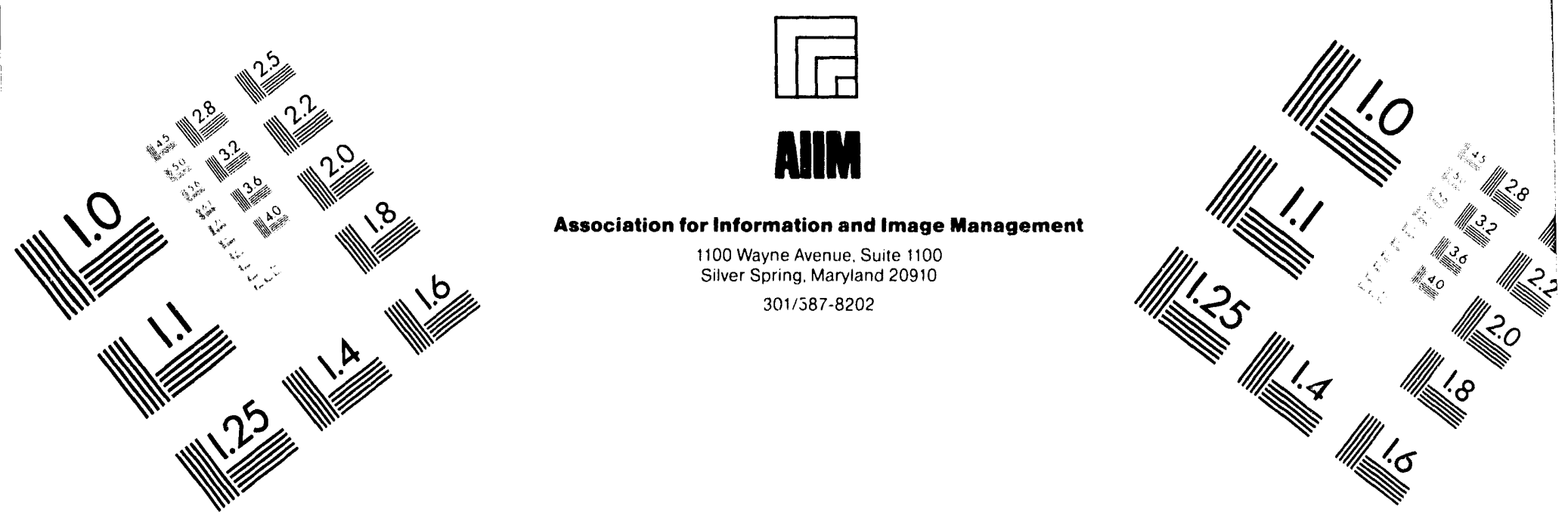

\title{
Centimeter
}

2
1 Inches
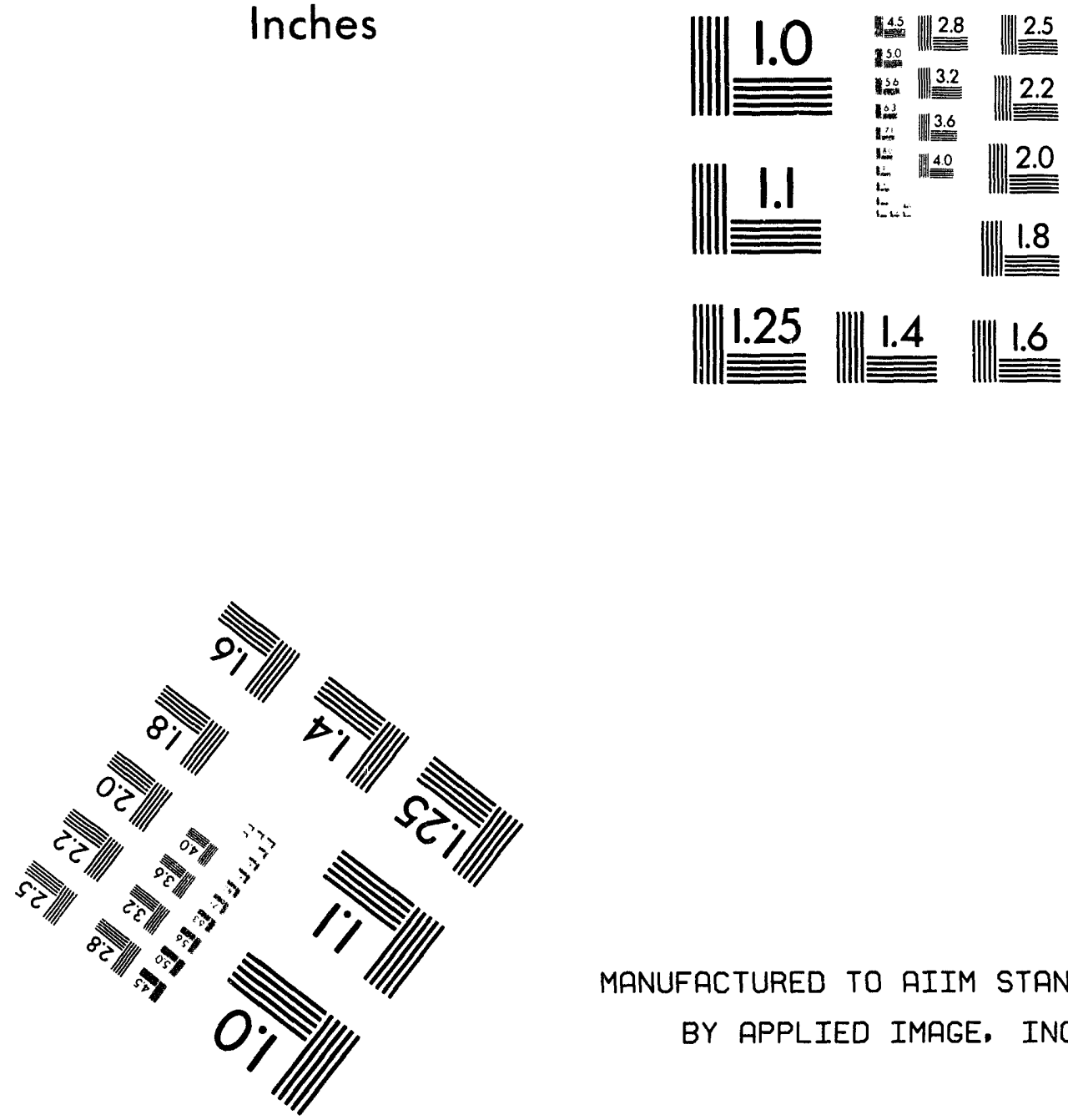

MANUFACTURED TO AIIM STANDARDS

BY APPLIED IMAGE, INC.

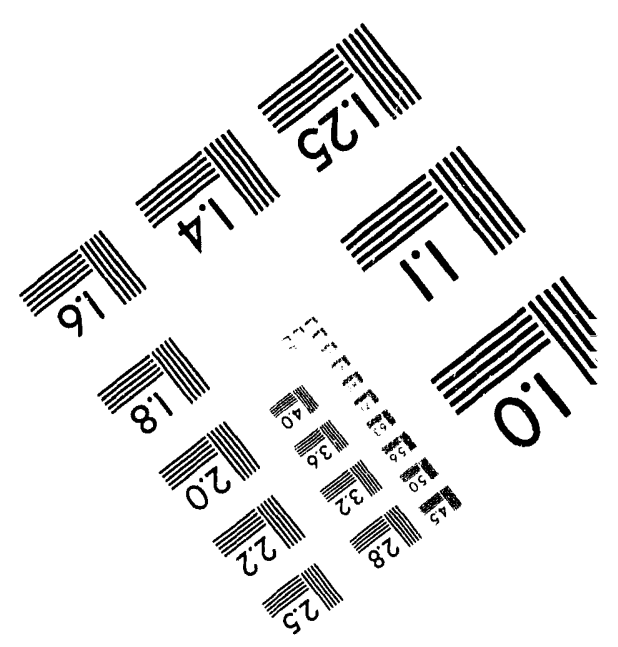



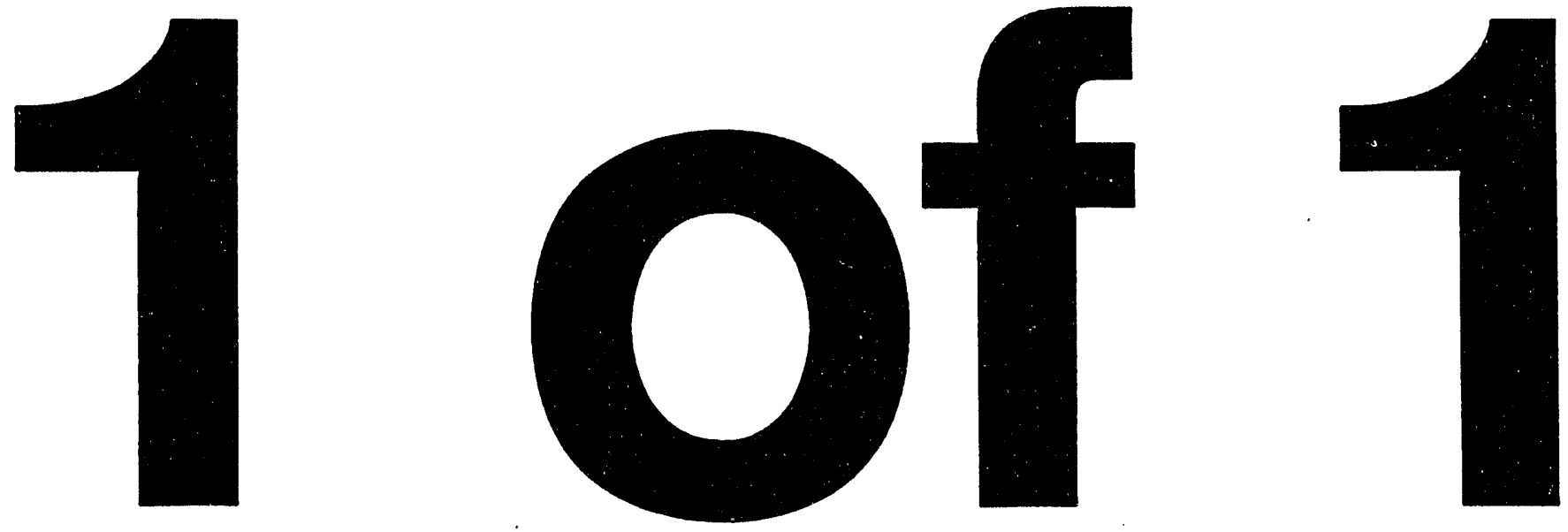


\title{
KAPL-4782
}

\section{ANALYSIS OF WELDING-INDUCED RESIDUAL STRESSES WITH THE ADINA SYSTEM}

\author{
W. W. WILKENING and J. L. SNOW
}

Prepared for

The United States Department of Energy

Prepared by

Knolls Atomic Power Laboratory

P. O. Box 1072

Schenectady, New York

Contract No. DE-AC12-76-SN00052 


\section{DISCLAIMER}

This report was prepared as an account of work sponsored by an agency of the United States Government. Neither the United States Government nor any agency thereof, nor any of their employees, makes any warranty, express or implied, or assumes any legal liability or responsibility for the accuracy, completeness, or usefulness of any information, apparatus, product, or process disclosed, or represents that its use would not infringe privately owned rights. Reference herein to any specific commercial product, process, or service by trade name, trademark, manufacturer, or otherwise, does not necessarily constitute or imply its endorsement, recommendation, or favoring by the United States Government or any agency thereof. The views and opinions of authors expressed herein do not necessarily state or reflect those of the United States Government or any agency thereof. 


$\begin{array}{lc} & \text { Page } \\ \text { Introduction } & 1 \\ \text { Background } & 2 \\ \text { Description of WIRSAP } & 3 \\ \text { Examples of WIRSAP Analysis } & 8 \\ \text { Conclusion } & 19 \\ \text { References } & 19\end{array}$

\section{FIGURE}

Fig.1 - Flow Chart for the Welding-Induced Stress Analysis Procedure(WIRSAP)

Fig. 2 - Schematic Illustration of the Modification of the ADINA-T temperature history file, to Simulate the "nodal birth" Process

Fig. 3 - Computed Welding-Induced Residual Stresses for a Two-Pass Pipe Girth Weld

Fig. 4 - Computed Welding History for the Element at the Center of the Weld on the Inner Surface of a Two-Pass Pipe Girth Weld(a) temperature (b) thermal strain

Fig. 4 - Continued, (c) plasticity flag (d) accumulated effective plastic strain

Fig. 5 - Computed Welding-Induced Residual Stresses for a Five-Pass Nozzle Attachment Weld

Fig 6 - WIRSAP Results for a Single-Pass Butt Welded Flat Plate (a) finite element mesh (b) longitudinal stress variation across the center of the plate

Fig 6 - Continued, (c) transverse stress variation along the weld centerline

Fig 7 - Comparison of Computed Welding-Induced Residual Axial Stresses in a 16-Pass Consumable Insert Attachment Weld Design Concept 
Fig. 8 - Comparison of Computed Welding-Induced Residual Axial Stresses in a 23-Pass Backing Ring Attachment Weld Design Concept

Fig. 9 - Finite Element Mesh, in the Vicinity of the Attachment Weld, for the 25-Pass Thick-Walled Nozzle Attachment Weld Design Concept, With an Integral Backing Ring

Fig. 10 - Computed Welding-Induced Residual Axial Stress in a 25-Pass Thick-Walled Nozzle Attachment Weld Design Concept, with an Integral Backing Ring, Upon Completion of Welding, and Prior to Removal of the Integral Backing Ring

Fig. 11 - Computed Welding-Induced Residual Axial Stress in a 25-Pass Thick-Walled Nozzle Attachment Weld Design Concept, with an Integral Backing Ring, after Removal of the Integral Backing Ring 


\title{
ANALYSIS OF WELDING-INDUCED RESIDUAL STRESSES WITH THE ADINA SYSTEM
}

\author{
W. W. WILKENING and J. L. SNOW \\ Knolls Atomic Power Laboratory, General Electric Company, Schenectady, NY 12301, U.S.A.
}

\begin{abstract}
The welding-induced residual stresses analysis procedure (WIRSAP), based on the ADINA system of nonlinear finite element software, is described and the results of several WIRSAP analyses are discussed. Several two-dimensional (2D) axisymmetric WIRSAP analyses have been performed for pipe girth welds and for several multi-pass girth-like welds attaching small nozzles to large, thick-walled pressure vessels. The analytical methodology follows closely the basic techniques outlined by Rybicki et al., enhanced by the use of several specialized modeling techniques available in the ADINA system. For example, the element birth option is used to simulate the addition of weld metal, and the mixed pressure/ displacement element formulation is used, in conjunction with the temperature-dependent bi-linear plasticity material model. Some of the welds analyzed involve backing rings, which were subsequently "machined off' via use of the element death option. The auto-time-stepping algorithm and the matrix update iteration scheme are used in the structural solutions. WIRSAP involves, in general, a pass-by-pass analysis of the uncoupled thermal and structural problems, but some analyses have been performed with an 'enveloping' technique for grouping several weld passes together to study the feasibility of modeling multi-pass welds on a layer-by-layer basis.

The analyses discussed here are all 2D, but most are large problems ( $>5000$ nodes and $>5000$ four-noded elements, with a large number of solution steps). As such, they pose significant challenges to both software and hardware resources. Pre- and post-processing operations are performed on a network of Silicon Graphics workstations, and ADINA and ADINA-T are executed on a $64 \mathrm{MW}$, eight-processor CRAY Y/MP. Nominally 50 solution steps are utilized for each weld pass, and weld joints involving as many as 31 individual weld passes have been analyzed on a pass-by-pass basis. Results from several of these WIRSAP analyses are discussed, and the potential use of WIRSAP in a hypothetic attachment weld design optimization study is illustrated.
\end{abstract}

\section{INTRODUCTION}

Welding-induced residual stresses (WIRS) are often a major contributor to the stress state in welded structural components, such as piping systems associated with chemical processing or power generation equipment (including nuclear power generation plants). Since weld metal shrinks as it solidifies and cools, welding-induced residual stresses are often likely to be predominantly tensile. The combination of tensile residual stresses induced by welding and the high-temperature aqueous environment typically associated with piping systems renders stress corrosion cracking (SCC) a major design consideration. Verification of structural integrity of such components against possible SCC failure therefore requires a reasonably accurate estimate of welding-induced residual stresses. Estimation of the remaining lifetime of operational components containing postulated stress corrosion cracks, in support of component life extension or repair/replacement decisions, requires an even more accurate estimate of the spatial variation of the residual stress state. For example, assessment of the potential for a leak-before-break situation involves prediction of crack growth into the self-equilibrating residual stress state. This, in turn, requires a rather

Knolls Atomic Power Laboratory, Schenectady, NY 12301, U.S.A. Operated for the U.S. Department of Energy by KAPL, Inc. under Contract No. DE-AC12-76SN00052. detailed knowledge of the welding-induced residual stress state throughout the component ard especially in the immediate vicinity of the weld, where SCC is most likely to occur.

In order to provide an adequate analytical capability for estimating welding-induced residual stresses for such purposes, a detailed analytical procedure was developed, using existing finite element codes and available modeling techniques. Thus far, application of this analytical procedure has been limited to twodimensional (2D) cases, but the procedure development has been done in such a manner as to permit subsequent extension to three dimensions (3D). Because of its previously demonstrated strengths in a wide variety of nonlinear analysis applications, the ADINA system of software was chosen as the foundation of the welding simulation procedure, which is named the welding-induced residual stress analysis procedure (WIRSAP).

WIRSAP is a system of commercially available finite element analysis codes (i.e., the ADINA system) and specialized pre- and post-processing utility programs, the associated material properties database, a set of specialized modeling techniques, and the rules and guidelines for using them for simulation of the welding process. A description of WIRSAP and a brief discussion of several WIRS analyses of hypothetical weld joints that have been performed in support of the development of WIRSAP are included herein. The intent is to provide sufficient detail to 
demonstrate the level of complexity of welding simulation that can be performed with (predominantly) commercially available general-purpose nonlinear finite element software.

The WIRSAP development strategy consists of the following five sequential phases:

1. Development of a 2D analytical procedure.

2. Sensitivity studies (in 2D) of the major input variables.

3. Extension of the procedure to 3D.

4. Qualification of the 3D procedure against measured residual stresses.

5. Development of simplified 2D (or quasi-3D) modeling techniques.

The development of WIRSAP is a 'work-inprogress'-at this writing, Phase 1 is completed, Phase 2 is nearing completion, and Phase 3 has been started. The end product will be a qualified 3D analytical procedure that can be used for pass-by-pass welding simulations, when needed. In addition, a more practical 2D (or quasi-3D) analytical procedure will also be developed, for more general 'production' use during the design of welded components. Suggestions for enhancements to the ADINA system that would serve to improve the efficiency of, or the accuracy of, WIRS analyses are discussed briefly, as well.

Since it is virtually impossible to produce a qualification weld that is characterized by a 2D residual stress state, it is judged that WIRSAP must be qualified in 3D. Two-dimensional investigation of the sensitivity of computed residual stresses and distortions to the uncertainties associated with various finite element modeling features and input parameters (e.g., element type and element formulation, mesh structure and refinement, details of heat input modeling, temperature-dependent material property assumptions, etc.) is a necessary precursor to the Phase 3 extension to 3D. The inclusion of truly 3D effects (e.g., the sequence of weld metal deposition and simulation of the movement of the heat source and of the associated molten zone) will permit qualification of the 3D analytical procedure against experimental residual stress data.

The 3D analytical procedure will be used to verify and qualify simplified modeling techniques for simulating important 3D effects via $2 \mathrm{D}$ or quasi-3D analysis and to determine the limits of applicability of such simplified methods. The qualified analytical procedure will also be used to develop parametric sets of solutions for various classes of weld joint configurations (e.g., pipe girth welds as a function of pipe size and schedule), so that routine design decisions can be supported without resorting to computationally intensive finite element analysis in every case.

\section{BACKGROUND}

Because of the geometric complexity of welded components, a general-purpose finite element-based welding simulation technique was sought. The estimation of WIRS by finite element techniques involves two distinct analysis steps: (1) a nonlinear thermal heat transfer analysis simulating the thermal history associated with the welding process and (2) a nonlinear structural analysis simulating the elastic-plastic deformation history of the welding process, following the thermal history computed in the thermal analysis.

The thermal and structural analyses are uncoupled, so the two analyses can be performed independently. It is assumed that, in general, both the thermal and structural portions of the WIRS analysis should be carried out on a pass-by-pass basis, with each weld bead application treated as a separate thermal transient, unless it can be shown that some level of grouping of weld passes is justified in a particular class of welding problem.

A brief review of the finite element-based welding simulation literature was conducted, with the aim of selecting a basic analytical methodology that could be quickly implemented with existing, commercially available, finite element software. Techniques relating to the analysis of multi-pass girth-like attachment welds in nonferrous materials were of primary interest. Consequently, work that placed special emphasis on the details of the thermal portion of the solution or upon the metallurgical modeling of phase transformation effects were not considered in any great detail (although these will have to be considered later).

Rybicki and co-workers at Battelle Columbus Laboratories and at the University of Tulsa have developed simplified finite element techniques for simulating welds in stainless steel piping [1-3]. While their work involves special thermal analysis methods and a special-purpose finite element program for the structural analysis, several examples of the use of ADINA-T and ADINA for welding simulation were also found. Most notable among these are the work of Josefson et al. [4], C. T. Karlsson [5], and R. I. Karisson and Josefson [6] in Sweden.

Many researchers have emphasized the details of the thermal analysis portion of the welding simulation, including the early finite element work of Friedman [7]. The more recent 'double ellipsoida،' model of Goldak and his colleagues at Carleton University for modeling heat input from the welding torch $[8,9]$ has been applied by Leung et al. to the analysis of a single-pass weld [10] and by Leung and Pick to the analysis of a multi-pass weld [11].

It can be argued that much of the detail of the high temperature excursion within the molten zone does not play a significant role in determining the residual stress level, however, since no substantial level of stress can be maintained above the solidus, anyway. Of course, accurate simulation of the time spent above the solidus temperature is required, so the heat transfer analysis outside the molten zone is adequately modeling. Also, the deposition of the correct amount of heat into the weld bead is required, so the thermal history of every point outside the molten zone and the 
cooldown history of the weld bead are adequately modeled. It is judged that this level of accuracy in the thermal portion of the welding simulation can be achieved by matching the computed thermal histories to measured thermal histories at several thermocouple locations near the molten zone, however.

Other analysts have emphasized the modeling of the important metallurgical effects of the solid state phase transformation that occurs in ferrous materials, including Dexter et al. from Southwest Research Institute [12].† Josefson et al. [4], C. T. Karlsson [5], and R. I. Karlsson and Josefson [6] all modeled the volume change associated with the phase transformation with their ADINA-based analytical technique, but not the associated transformation plasticity effects and other aspects of the metallurgical simulation. At MIT, Papazoglou and Masubuchi [14] have used ADINA to model the metallurgical transformationsand to account for the associated volume change. Since only non-ferrous materials were initially of interest here, however, phase transformation effects have not yet been considered in WIRSAP. This, too, will have to be addressed in the future.

On the basis of the review, it was concluded that the relatively straightforward welding simulation techniques of Rybicki et al. [1-3], coupled with a relatively standard finite element-based (conduction only) thermal transient analysis, would provide an appropriate basis for the development of WIRSAP, without requiring any finite element programming effort. In addition, it was concluded that, with the exception of phase transformation modeling capabilities, the ADINA system of nonlinear finite element software embodied all the finite element modeling features likely to be needed for simulating welding processes [15]. This paper demonstrates that this is, in fact, the case.

Although the basic techniques of Rybicki et al. [1-3, 15] were followed in the development of WIRSAP, there is also a great deal of similarity to the other ADINA-based techniques of Josefson et al. [4], C. T. Karlsson [5], R. I. Karlsson and Josefson [6], and Papazaglou and Masubuchi [14]. The salient features of the resulting WIRSAP are described in the following section.

\section{DESCRIPTION OF WIRSAP}

\section{Overview}

The flowchart for WIRSAP, which is shown in Fig. 1, illustrates the various programs and steps involved in both the thermal and structural analysis portions of a WIRSAP analysis. The left-hand side of the flowchart illustrates the steps involved in the thermal analysis, while the right-hand side illustrates

tThe Southwest Research Institute (SWRI) review of available welding simulation software [13], published recently by the Electric Power Research Institute (EPRI) provides an excellent up-10-date summary of welding simulation approaches.

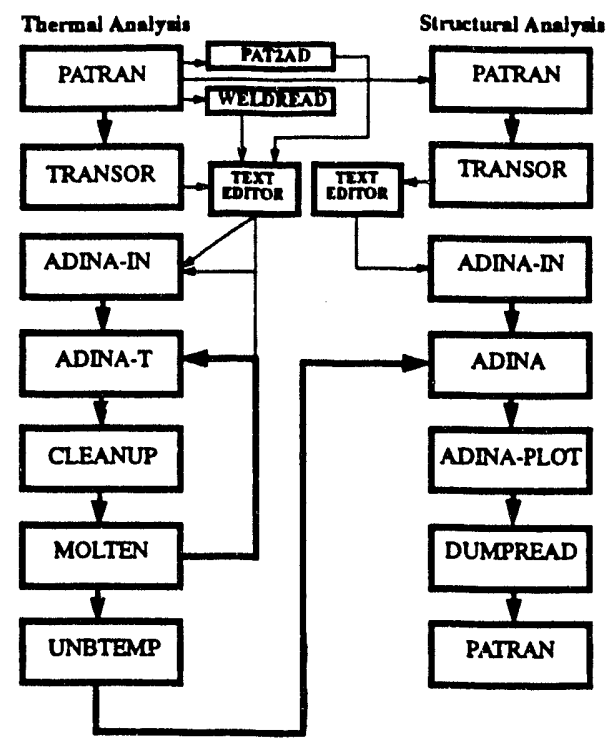

Fig. 1. Flowchart for the welding-induced residual stress analysis procedure (WIRSAP).

the steps involved in the structural analysis. Both sides of the WIRSAP flowchart are built around the basic ADINA nonlinear finite element software system, which consists of a pre-processor (ADINA-IN), a nonlinear thermal analysis code (ADINA-T), a nonlinear structural analysis code (ADINA), and a post-processor (ADINA-PLOT).

In general, several (typically three or four) 'openloop' iterations on the thermal solution are required to adequately match the molten zone size and shape. In cases for which measured thermal history data is available from a welded mock-up of the component being analyzed, a second series of 'open-loop' thermal solution iterations are performed in order to match the measured thermal histories.

The end product of the thermal analysis is a temperature history file, which becomes the input to the structural analysis, which uses the same finite element (FE) mesh as the thermal analysis. In the structural analysis, the temperature history file resulting from the thermal analysis is the only 'load'. Elastic-plastic deformation of the sequential welding process is modeled on a pass-by-pass basis by incrementally following the computed pass-bypass welding thermal history. The auto-time-stepping (ATS) algorithm is used, in conjunction with automatic interpolation on the input temperature history file, to reduce the need for analyst intervention to a minimum.

While only 2D axisymmetric analyses have been performed with WIRSAP to date, there is nothing in the technical procedure itself that limits its use to $2 \mathrm{D}$ analysis. In fact, efforts to extend WIRSAP to $3 D$ have recently been initiated.

\section{The ADINA software system}

Ordinary ADINA-T or ADINA analyses would use only the four basic codes of the ADINA software 
system, since ADINA-IN has self-contained meshgeneration capabilities and ADINA-PLOT has results analysis and plotting capabilities. When PATRAN is used for finite element model generation, load and boundary condition application, etc., and also for post-processing, however, TRANSOR provides both pre- and post-processing interfaces between PATRAN and either ADINA-IN or ADINA-PLOT. WIRSAP utilizes PATRAN and TRANSOR in essentially this manner, so that ADINA-IN and ADINA-PLOT, which are normally used in interactive mode in the basic ADINA software system, are essentially reduced to batch mode file translators.

\section{WIRSAP utility software}

T) provide the several special capabilities needed for simulation of the welding process, a set of specialpurpose utility programs have been developed as part of WIRSAP, for the purpose of automating some of the more tedious steps in the preparation of the ADINA-T and ADINA input files. While the functions that these programs serve are important to WIRSAP, the programs themselves are mainly specialized text editors, and we only briefly describe some of the functionality below. Some of these programs were developed prior to the production release of TRANSOR, and will be replaced by use of TRANSOR.

MOLTEN. The utility program MOLTEN reads the binary temperature file and prepares a PATRAN nodal results file that can be displayed on the workstation to illustrate the molten zone. MOLTEN also prepares a thermal history plot file that can be displayed with WPLOT, a TEKTRONIX-based X-Y plotting program that runs on a VAX computer. When inspection of these two forms of thermal postprocessing results indicates that an acceptable thermal solution has been achieved, certain modifications (to be described below) are made to the resulting output temperature history file. This modified temperature history file becomes the input for the structural ADINA run.

UNBTEMP. When convergence on the molten zone size and/or temperature history at selected locations has been achieved after several 'open-loop' iterations through ADINA-T, UNBTEMP is used to modify the temperature history file for input to ADINA. The modifications, which are illustrated schematically in Fig. 2, consist of truncating any computed temperatures to the 'softening temperature' and holding the temperature of nodes that belong exclusively to elements modeling weld metal that has not yet been deposited (i.e., the 'unborn nodes') at the 'softening temperature' until the 'birth time' for the associated elements.

Note that for the purposes of the thermal portion of WIRSAP, the 'melting temperature' is taken to be (roughly) the solidus temperature, not the liquidus temperature. This is, in turn, taken to be $1644 \mathrm{~K}$ $\left(2500^{\circ} \mathrm{F}\right)$ for all the materials of interest in this program. For the purposes of the structural portion of WIRSAP, the 'softening temperature' is taken to be the temperature at which the yield strength and hardening modulus reduce to a mathematically convenient limiting value, e.f., $\sim 7 \mathrm{MPa}(1 \mathrm{ksi})$. The 'softening temperature' is 'aken to be $1422 \mathrm{~K}\left(2100^{\circ} \mathrm{F}\right)$.

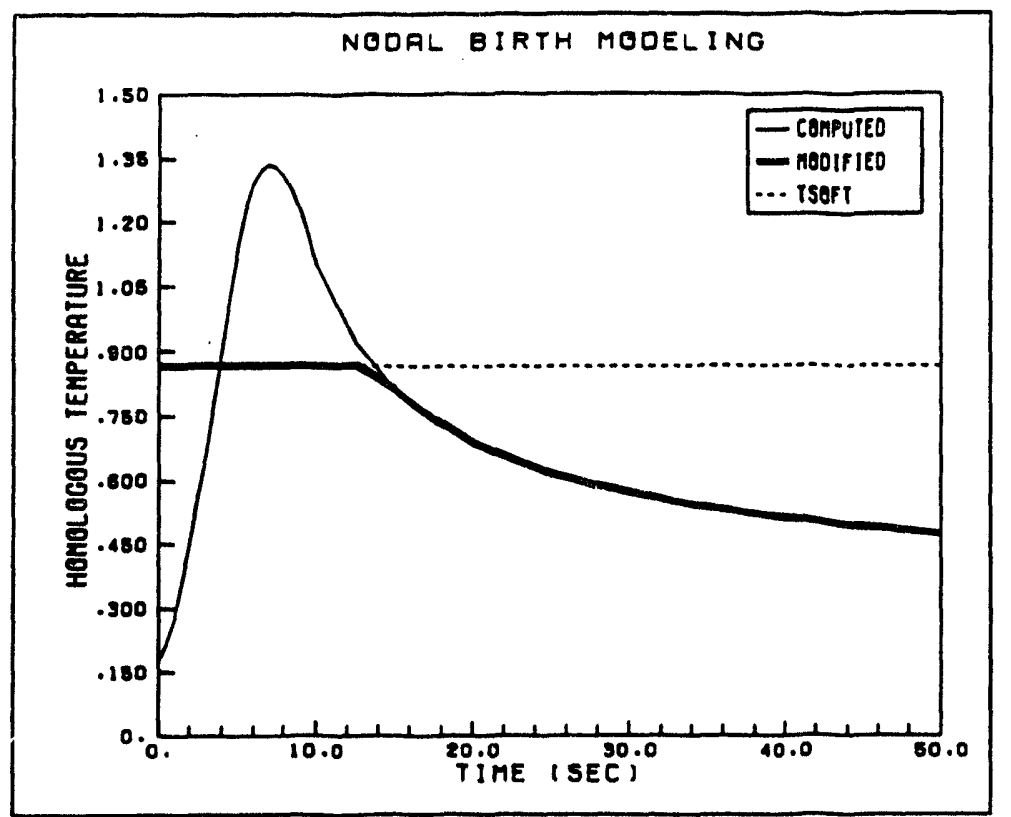

Fig. 2. Schematic illustration of the modification of the ADINA-T temperature history file, to simulate the 'nodal birth' process. The computed thermal history (solid line) is truncated at the 'softening temperature' (dotted line), to produce the modified thermal history (heavy line) that simulates the stress-free 'birth' of weld element nodes at the 'softening temperature'. 
DUMPREAD. DUMPREAD reads the DUMP. FILE created by ADINA-PLOT from the structural analysis output post-processing file and creates a series of PATRAN element centroidal results files and nodal displacement files, which are disposed back from the CRAY to the workstation network for display with PATRAN. The element centroidal results are computed simply by averaging the integration point quantities within each element.

CLEANUP. CLEANUP performs the simple function of cleaning up some of the ADINA-T output, for our specialized use. Therefore, the action of CLEANUP is a convenience, but is otherwise irrelevant to the solution process.

\section{Other auxiliary utility programs}

The production version of TRANSOR used in this work only supported the structural code, ADINAnot the thermal code, ADINA-T. Therefore, the translation from PATRAN to ADINA-T temporarily involves a significant amount of manual file manipulation, involving a few small, special-purpose utility programs and some text editing, as indicated in Fig. 1. In addition, some small amount of file editing is required in both the thermal and structural analyses to prepare the 'READFILE' required by ADINA-IN. The 'READFILE' contains the WIRSAP material property database, the solution timestep block information, and the time functions. In addition, in the thermal analysis, the 'READFILE' also contains the fixed boundary temperatures and concentrated nodal heat fluxes, which can be prepared by the program PAT2AD. PAT2AD reads the PATRAN neutral file, extracts fixed nodal temperatures and concentrated nodal heat fluxes, and writes them to a pair of files in the proper format for inclusion in the ADINA-IN 'READFILE'.

WELDREAD also reads the PATRAN neutral file and extracts information from NAMEd components $\dagger$ of the form 'WELDnn', where $\mathrm{nn}$ is the weld pass number. The NAMEd components contain the nodes that are to be considered 'unborn' for the purposes of UNBTEMP. The output file from WELDREAD, after a small amount of editing, becomes an input file for UNBTEMP.

\section{Execution of WIRSAP}

Virtually all of the pre-processing steps for both the thermal and the structural analyses are performed on the SGI workstation network, using PATRAN,

†The PATRAN command NAME provides a convenient facility for grouping selected geometric or finite element entities (e.g., grids, patches, nodes, elements, etc.) together for reference by the user-assigned NAME. NAMEd components appear in the PATRAN neutral output file as lists of entity ID numbers. It is convenient to plot the nodes associated with a given weld pass and NAME them as WELDnn (where $\mathrm{n} n$ is the weld pass number). See the PATRAN user manual, Vol. I, Chap. 15 for a complete description.
TRANSOR, the utility programs, and a text editor. The temporary utility program PAT2AD runs on the VAX, however. It will be replaced by TRANSOR. The end product of this series of steps is an input file for ADINA-IN that contains, or refers to, all required input data for the ADINA-T or ADINA analysis. ADINA-IN reads this file and produces the card image input file that actually executes ADINA-T or ADINA. Both ADINA-T and ADINA run on the CRAY, as does ADINA-PLOT (which reads the binary post-processing file produced by the structural ADINA run and prepares a formatted ASCII postprocessing file called the DUMPFILE) and the two thermal analysis utility programs MOLTEN and UNBTEMP. The post-processing translator DUMPREAD can be run on either the CRAY or the workstation. Generally, both ADINA-PLOT and DUMPREAD are executed automatically at the end of the ADINA structural analysis, so a single job submittal to the CRAY ends with PATRAN post-processing files being disposed back to the workstation. The output print file and the binary temperature history file (for ADINA-T thermal analyses) or the DUMPFILE (for ADINA structural analyses) are automatically archived upon completion of the job.

\section{WIRSAP thermal analysis}

The primary or unique features of the thermal analysis portion of a WIRSAP analysis are described in the following sections.

WIRSAP thermal material properties. The thermal analysis portion of WIRSAP utilizes temperaturedependent thermal properties-thermal conductivity and specific heat. In general, both properties are assumed to increase linearly with temperature from $255 \mathrm{~K}\left(0^{\circ} \mathrm{F}\right)$ to the melting temperature-1644 K $\left(2500^{\circ} \mathrm{F}\right)$, and are assumed to be constant at and above the melting temperature. Exceptions to this are the thermal properties for low-alloy steel. For this ferrous material, the specific heat exhibits a triangular 'spike' between $811 \mathrm{~K}\left(1000^{\circ} \mathrm{F}\right)$ and $1089 \mathrm{~K}\left(1500^{\circ} \mathrm{F}\right)$, to account for the thermal effect of the solid-state phase transformation that occurs in the vicinity of $1033 \mathrm{~K}\left(1400^{\circ} \mathrm{F}\right)$. Similarly, the thermal conductivity exhibits nonlinear behavior with temperature, also because of the phase transformation.

The WIRSAP thermal property database is tabulated in the format required by ADINA-IN, and is inserted via a 'READ' command inserted in the ADINA-IN input file, which causes ADINA-IN to read in data from an auxiliary 'READFILE'. The 'READFILE', which contains a copy of the WIRSAP thermal material property database, also contains some other problem-specific information. This includes the solution timestep blocks, the time functions that control the 'loads', and the thermal 'loads' themselves-the fixed boundary temperatures and the concentrated nodal heat fluxes. 
The 'READFILE' is prepared by the analyst, using a text editor and the utility programs discussed earlier.

Element 'birth' option. In the thermal analysis, the sequential addition of new weld metal is modeled with the ADINA-T element 'birth' option, which provides a means for activating elements at a prescribed (solution) time. Removal of material (e.g., removal of backing rings via machining) is modeled in an analogous fashion with the element 'death' option, which de-activates elements at a prescribed (solution) time. In cases involving the subsequent removal of previously deposited weld metal, the 'birth-then-death' option may be used.

Weld elements are activated in the finite element model at the (solution) time at which the molten weld metal would be deposited. This is also the 'arrival time' for the concentrated nodal heat flux input for the weld elements. Consequently, the thermal mass and the heat flow conditions accurately portray the sequential deposition of the weld metal (at least in the $2 \mathrm{D}$ approximation sense, in which the entire length of weld bead is assumed to be simultaneously deposited). The elements associated with a given weld bead belong to a separate element group, and all of these elements have the same 'birth' time. When WIRSAP is extended to 3D, each 'slice' of the elements along the weld pass will be 'born' sequentially, to simulate the sequential advance of the welding torch. All elements belonging to a given weld pass will still belong to a separate element group, but each element will (in general) have a unique 'birth' time.

Heat input modeling. Heat input is modeled by concentrated nodal heat flux at the nodes that are internal to the weld pass that is currently being applied. The heat flux is applied in accordance with an assumed triangular time variation (i.e., a linear upramp followed by a linear down-ramp, with no "hold time'). This technique applies a spatially uniform heat flux input to (typically) $\sim 3 / 4$ of the cross-sectional area of the current weld pass and the triangular shape of the time function simulates the approach and passing of the welding torch. The up-ramp starts at the element 'birth time' for the elements associated with the current weld pass. The heat subsequently flows into the surrounding elements by conduction, resulting in a molten zone that is larger than the area to which the heat was initially applied. Elemental internal heat generation can equally well be used to model the heat input, but the concentrated nodal heat flux method has been used in most of the analyses conducted to date.

Heat flow modeling. The class of welding problems of interest in this work program involves relatively small attachments to thermally and structurally massive components. It is considered reasonable to assume that most of the heat flow in such cases is due to conduction away from the weld puddle and into the thermally massive structural component. Consequently, convection and radiation losses are not modeled (although either or both could be added, if necessary). The ADINA-T implementation of both convection and radiation requires that each convecting or radiating surface of $2 \mathrm{D}$ (or $3 \mathrm{D}$ ) conduction elements be 'paved' with ID (or 2D) convection and/or radiation elements. This would be quite awkward for WIRS analyses, since only the current outer surface of the partially completed weld would be a convecting or radiating surface at any given time. Thus, each convection or radiation element would, in general, be subject to the 'birth-then-death' option.

Heat of fusion. ADINA-T has the capability of modeling the heat of fusion associated with melting and solidification, but the solution algorithm is such that this modeling technique cannot be used in conjunction with the element 'birth' option. Since the use of the element 'birth' option is of greater importance in this type of analysis, the heat of fusion has been ignored instead. This is entirely consistent with the other thermal modeling techniques employed in WIRSAP - heat transfer in the liquid (or two-phase) state is not accounted for, since no temperatures above the 'softening temperature' are admitted to the structural solution anyway.

Heat of fusion is ignored on both the heatup and the cooldown, so the two effects partially cancel each other out, in a crude sort of way. More significantly, the methodology used to choose the 'correct' heat (power) input can be interpreted to include the net effect of the heat of fusion and other such effects, anyway. The whole WIRSAP structural analysis is confined to the solid state, since all stresses would be (essentially) wiped out above the 'softening temperature'. Therefore, the behavior of the thermal solution above the solidus is not judged to be terribly relevant.

Unique WIRSAP thermal solution details. There is no way to know a priori the 'correct' magnitude of heat flux or the 'correct' heatup and cooldown 'ramp' rates to use in this type of thermal simulation of the welding process. In addition, in the case of a $2 \mathrm{D}$ axisymmetric approximation to what is in actuality a 3D heat flow problem, another level of approximation is involved by virtue of the need to simulate (somehow) the effects of circumferential heat flow. Therefore, it is, in general, necessary to conduct an 'open-loop' iteration on these input parameters in order to achieve an adequate thermal solution. In this iterative process, values of the heat input parameters are assumed in a trial thermal solution and the results are compared, in an 'open-loop' manner, to known thermal history results.

Ideally, this iterative 'loop' would consist of two separate phases. In the first phase, the amount of heat input would be adjusted until the molten zone size was 'correct', while holding the heatup and cooldown rates constant at some assumed value (determined 
on the basis of previous analytical experience, for example). The magnitude of the concentrated nodal heat flux would be adjusted, by modifying the magnitude of the triangular time function that controls the heat flux, for each of the separate trial thermal analyses. In the second phase, the heatup and/or cooldown rates would be adjusted, by modifying the up- and/or down-ramp portions of the nodal heat flux time function (keeping the area under the time function constant, so the total amount of heat input was held constant), until the computed thermal history matched the measured thermal history at a series of thermocouple locations that had been monitored during the actual welding of a mock-up of the component. Minor adjustments to the magnitude of the heat flux may be required in the second phase, to keep the molten zone size 'correct', but this is only a second-order effect.

In practice, however, there is typically insufficient time (analyst's time, as well as computer time) available to complete both phases of this iterative process Also, thermocouple data are not always available to support the second phase of iteration-especially in the important case of analysis of a conceptual design. Thus, it has been the usual practice to assume the heatup and cooldown ramp rates (in fact, both rates have been assumed to be the same) and simply iterate to achieve a reasonable molten zone size. Clearly, more development work is required in this area to improve this process.

\section{WIRSAP structural analysis}

The primary or unique features of the structural portion of a WIRSAP analysis are described in the following sections.

WIRSAP structural material properties. The structural analysis portion of WIRSAP utilizes temperature-dependent structural properties-elastic modulus, yield strength, hardening modulus, and mean coefficient of thermal expansion. ADINA requires the mean coefficient of expansion, which leads to the necessity of defining the coefficient of expansion with respect to the 'softening' temperature for the weld material (i.e., the reference temperature equals the 'softening' temperature). This ensures that the newly 'born' weld elements are thermal strain-free. It would be a great convenience if ADINA utilized the instantaneous thermal expansion coefficient, instead of the mean coefficient of thermal expansion.

In ADINA, the temperature-dependent elasticplastic material model uses a bi-linear representation of the stress-strain curve. This is defined by the elastic modulus, Poisson's ratio, the yield strength, and the hardening modulus. The hardening modulus is the slope of the bi-linear approximation to the stress-strain curve above the yield point.

The WIRSAP structural property database is tabulated in the format required by ADINA-IN. Both isotropic and kinematic hardening plasticity rules are available in ADINA, so the WIRSAP database contains both versions of input data. Except for the word 'ISOTROPIC' or 'KINEMATIC', the two versions of the database are identical.

The structural material property database is inserted via a 'READ' command inserted in the ADINA-IN input file, which causes ADINA-IN to read in data from an auxiliary 'READFILE'. The 'READFILE', which contains a copy of the WIRSAP structural material property database (either the isotropic or the kinematic version, as desired by the analyst), also contains some other problem-specific information. This includes the solution timestep blocks and any time functions required for control of other loads to be applied to the model upon completion of the welding simulation analysis. The 'READFILE' is prepared by the analyst, using a text editor and the utility programs discussed earlier.

Nodal 'birth' modeling. In the structural analysis, the temperature history file resulting from the thermal analysis is the only 'load'. Elastic-plastic deformation of the sequential welding process is modeled on a pass-by-pass basis by incrementally following the computed pass-by-pass welding thermal history. However, in order to simulate the sequential addition of each weld pass in the structural analysis, and to implement the 'solid-state modeling' methodology discussed earlier, nodes belonging solely to elements in weld passes that have not yet been deposited are held at the 'softening' temperature until what would be the 'birth time' of the associated elements.

For the structural analysis, the appropriate 'nodal birth time' is the (solution) time at which the computed nodal temperature falls to the level of the 'softening temperature' (note that this is different from the definition of 'birth time' used in the thermal analysis). This definition implies that a node, and the associated element, are structurally inactive (i.e., 'dead') until the node cools down to the softening temperature. While a node is above the melting temperature, it is liquid and carries no stress; while it cools from the melting temperature to the 'softening temperature', it is actually structurally active (i.e., 'alive'), but it still carries essentially no stress.

As long as heat is being added to nodes in the current weld pass at a rate greater than the rate at which heat is flowing out of the associated element, that element should be structurally inactive. This effect is achieved by holding the nodal temperature at the 'softening temperature' until the (solution) time at which the nodal temperature reaches the 'softening temperature' on the cooldown, as shown schematically in Fig. 2. Thus, even though the weld elements are always active in the structural solution, they can only carry stresses on the order of $7 \mathrm{MPa}(1 \mathrm{ksi})$, so they are effectively inactive.

UNBTEMP is used to modify the temperature history file from the ADINA-T thermal analysis in 
the following manner, to effectively implement this definition of 'nodal birth time'.

1. For all nodes that belong only to elements modeling weld passes that have not yet been deposited, UNBTEMP holds computed nodal temperatures at the 'softening temperature'- $1422 \mathrm{~K}\left(2100^{\circ} \mathrm{F}\right)$ until the specified estimate of the 'birth time' for the elements that model the current weld pass.

2. For all nodes in the model, UNBTEMP truncates any computed nodal temperature to the 'softening temperature'- $1422 \mathrm{~K}\left(2100^{\circ} \mathrm{F}\right)$.

The effect of these two modifications is to eliminate the heat-up portion of the thermal history for all nodes associated with the current weld pass, and to hold the nodal temperatures at the 'softening temperature' until the time at which that node was computed to cool down to the 'softening temperature'. Since this results in a unique 'birth time' for each node, it is convenient to provide UNBTEMP with al. estimated lower bound on the nodal 'birth time' by specifying the time at which the maximum molten zone size occurs.

Nodes that are shared by 'unborn' elements and 'active' elements are treated as 'active'. (This is in contrast to the technique of C. T. Karisson [5], who treats the shared nodes as part of the weld metal.) This whole process amounts to the simulation of a 'nodal birth option', in place of the 'element birth option' and gives better control for the analysis.

Element 'death' option. In a manner similar to the use of the element 'birth' option in the thermal analysis, the element 'death' option (which de-activates elements that were initially active) can be used in WIRSAP to model the removal (e.g. by machining) of material at pre-specified (solution) times.

Unique WIRSAP structural solution details. Using the modified temperature history file as the only input 'load', the structural ADINA analysis proceeds as any ordinary elastic-plastic structural analysis, with a few notable exceptions.

1. The mixed displacement/pressure (U/P) element formulation available in ADINA is used to eliminate problems associated with 'volumetric locking'. 'Volumetric locking' produces a checkerboard-like oscillation in computed stresses whenever the deformation is sufficiently incompressible. This occurs in the high temperature regime experienced by the elements modeling the weld metal, for which the yield strength and the flow stress are so low that the plasticity almost completely dominates the deformation.

2. The matrix update iteration scheme is used to achieve equilibrium. This very powerful and robust equilibrium iteration scheme is capable of efficiently handling the several significant nonlinearities involved in WIRSAP analyses. A full Newton iteration scheme is also available in ADINA, and it achieves equal computational efficiency.

3. The ATS algorithm, in conjunction with automatic interpolation on the input temperature history file, is used to minimize the need for user intervention during the structural solution.

4. A minimum of 16 four-noded quadrilateral elements are used to model each of the weid passes, and the aspect ratio of these elements is kept as close to unity as possible.

Analyses performed to date have used nominally 50 solution steps per weld bead. All 50 solution steps are passed on to the structural analysis, which uses the same 50 timesteps, but with the ATS algorithm activated. Consequently, interpolation on the temperature file is sometimes required, but this is done automatically by ADINA. Further studies of the solution stepsize are planned; it is expected that significant reductions in the number of steps can be made.

\section{EXAMPLES OF WIRSAP ANALYSES}

The results of several WIRSAP analyses are discussed briefly in the following section, to illustrate several important features of WIRSAP and 10 demonstrate its capabilities.

\section{Two-pass pipe girth weld}

A two-pass pipe girth weld has been used to conduct most of the WIRSAP development and verification work and for most of the initial sensitivity studies. Studies of mesh refinement, the use of matrix update vs full Newton vs modified Newton iteration algorithms, the use of nine-noded vs four-noded elements, ATS, mixed variational formulation element formulation, solution step size, large-displacement formulation, etc., have all been conducted with this simple problem. This two-pass example contains all the features of a multi-pass weld, but is still so small that the solutions require only a few minutes of CPU time. Initial studies directed at extending WIRSAP to 3D will also be performed with this problem, but these have just recently begun.

Thermal history, deformation, and residual stress data for this consumable insert weld in a $324 \mathrm{~mm}$ (12.75 in) diameter pipe with a $4.57 \mathrm{~mm}$ (0.18 in) wall thickness (i.e., a 12-in schedule 10 pipe) are available in [1] and more detailed results were obtained from [15]. Very good agreement with the measured thermal history at the several thermocouple locations can be achieved by adjusting the amount of heat added to the weld metal and by adjusting the time period for the heatup and cooldown portions of the welding thermal transient, as discussed earlier.

Good agreement with measured residual stresses can also be achieved. For this thin-walled pipe geometry, both the hoop and axial components of the residual stress are tensile on the inner diameter (ID) in the weld and adjacent heat affected zone 

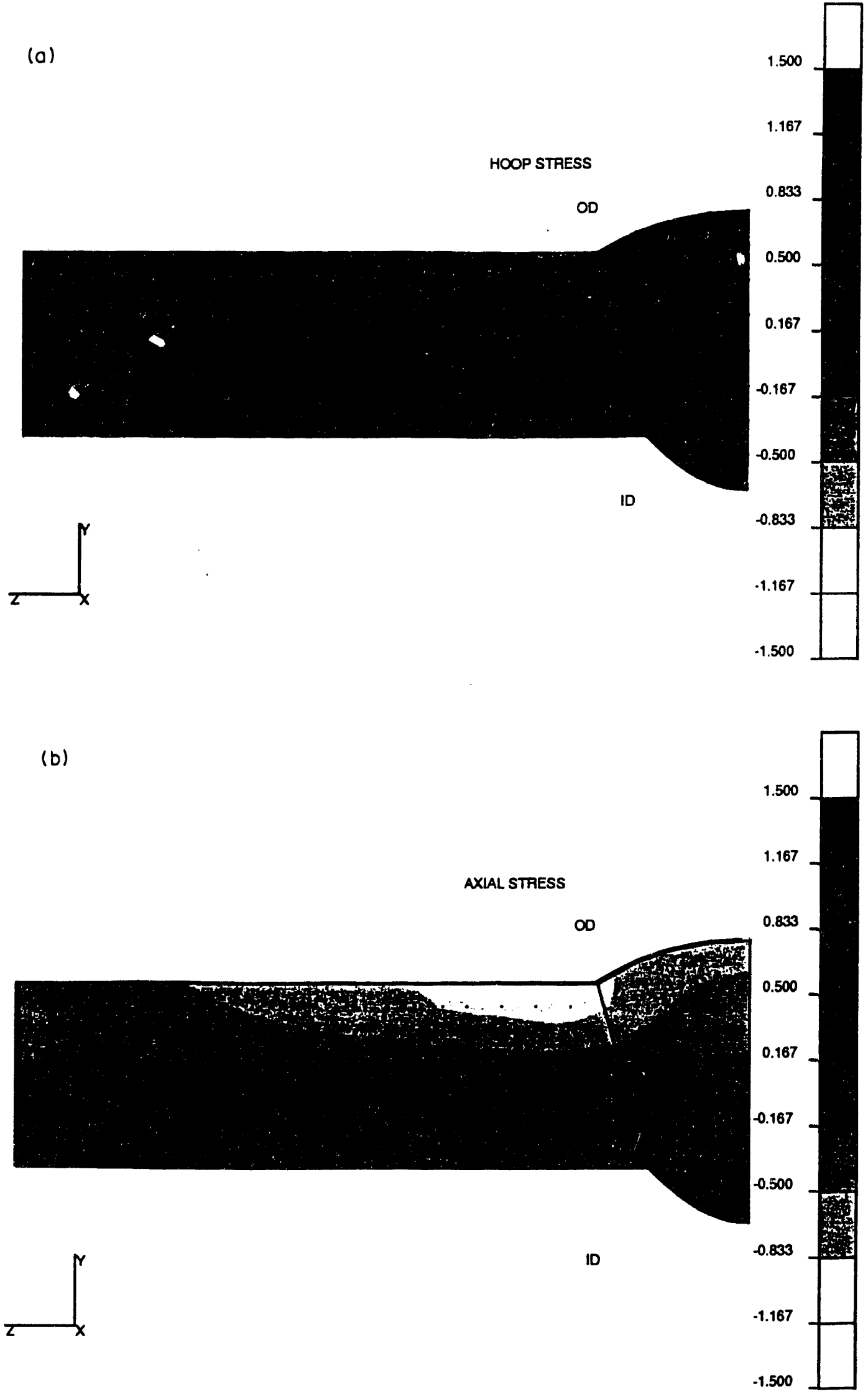

Fig. 3. Computed welding-induced residual stresses for a two-pass pipe girth weld (normalized by the room temperature yield strength of the weld metal): (a) hoop stress: (b) axial stress. 
(HAZ), as shown in Figs 3(a) and (b), respectively. These figures represent the current 'standard' use of WIRSAP, including the use of four-noded quadrilateral elements with the mixed variational formulation (U/P formulation with one pressure degree-of-freedom), small displacement, small strain formulation, $2 \times 2$ integration, and the matrix update iteration scheme.

The gray-scale fringe plots were prepared with PATRAN, from element centroidal results generated by DUMPREAD by averaging the results from the four integration points. In this and subsequent stress result figures, the stresses have been normalized by the room temperature yield strength of the weld metal. Also, the finite element mesh is not shown, for clarity. The outlines of the individual weld passes are illustrated, however.

The figures demonstrate that, within the weld and adjacent region, the axial stress varies almost linearly through the wall at a given axial position, with essentially zero mean stress (i.e., pure bending). The hoop stress is tensile through the whole wall thickness, in the weld and HAZ. This type of stress state is entirely representative of girth welds in thin-walled pipes, and provides the fundamental explanation for piping system susceptibility to SCC attack.

The computed displacements (both axial and radial) underestimate the measured displacements by a substantial amount, however (e.g., by a factor of 2). The explanation of this commonly observed result is embodied in the $3 \mathrm{D}$ nature of the actual weldment, in which only a small portion of the pipe is hot at any one instant. Most of the plastic deformation occurs in compression (i.e., upsetting) in the hot portion of the pipe. This is due to the constraining effect of the much larger portion of the pipe that is relatively cool, stiff, and strong. These portions of the pipe will not (indeed, cannot!) expand through the $\sim 2 \%$ thermal strain associated with heating up from ambient to melting temperature. Instead, the hot material in and around the weld yields in compression during the heat-up portion of the welding transient. When the whole component later cools, the associated displacements are locked in because the thermal stress has been largely dissipated by the upsetting and the yield strength has increased as the temperature fell.

Upon application of a subsequent weld layer, the process repeats, but the displacements from the previously deposited weld layers remain. Roughly

tThe plasticity flag has a numeric value of 1.0 for elastic conditions and 2.0 for plastic conditions, at each integration point. Therefore, when all four integration points are elastic, the element centroidal value of the flag is 1.0 , and the element centroidal value is 2.0 when all four integration points are currently yielding; thus, values of $1.25,1.5$, and 1.75 are also possible.

\pm Note that, since these plots refer to an element of weld metal, the reference temperature is equal to the 'softening temperature'. Therefore, the thermal strain is zero initially, becoming negative as the weld metal cools. the same amount of displacement accumulates from plastic upsetting on each subsequent weld layer, in a process that can be referred to as 'compressive ratcheting'. This phenomenon is no small source of difficulty with respect to fit-up concerns associated with the welding of piping systems and especially with regard to repeated weld repairs in a run of piping.

Since WIRSAP does not currently utilize the large displacement formulation, the geometry of the FE mesh is not updated. Consequently, while the accumulated effective plastic strain continues to increase, the computed nodal displacements do not reflect the 'compressive ratcheting' effect. Rybicki et al. [1-3, 15], in their special-purpose welding simulation code, WELD3, perform a geometrically linear structural analysis, but the geometry is updated between weld passes. Techniques for accomplishing this with ADINA will be investigated in the future. In addition, modeling techniques that simulate the constraint of the cooler portion of the circumference without resorting to $3 \mathrm{D}$ analysis are also being considered. C'ne possibility is the use of a parallel set of elements to model the cooler portion of the 3D component. Perhaps truss elements could be used for this purposeconnecting the two portions of the weldment together in both axial and hoop directions.

Examinations of the history of the individual stress components and of the plasticity flag (which tells whether an integration point is currently elastic or plastict) during this two-pass pipe girth weld analysis demonstrate that yielding occurs during the heat-up portion of the welding transient and continues in the cooldown portion until the temperature reaches about $0.3 \mathrm{~T}_{\text {melt }}$ (i.e., about $500 \mathrm{~K}$, about $300 \mathrm{sec}$ into the welding transient.

This is demonstrated in Figs $4(a)-(c)$, which illustrate the history of the temperature, the thermal strain, $\ddagger$ and the plasticity flag, respectively, for the first pass element located at the center of the weld and at the ID surface. However, as Fig. 4(d) illustrates, nearly all of the plastic strain is developed within the first $\sim 100 \mathrm{sec}$, while the temperature is high and the yield strength is low. Consequently, the residual stress state largely reflects the yield strength at $\sim 500 \mathrm{~K}$ (in this example).

In this two-pass weld, the second pass reheats the first pass sufficiently to largely wipe out the first-pass residual stress state. Therefore, a single-pass simulation of the weld yields essentially the same residual stress state as the two-pass simulation. For the much thicker girth-like nozzle attachment weld to be discussed below, this is not the case, however.

\section{Five-pass nozzle attachment weld with backing ring}

This is a girth-like weld attaching a small nozzle to a large pressure vessel, so there is a lack of symmetry across the center of the weld gap, and there are now five weld passes in $\sim 3$ layers. Otherwise, there is not much difference between this weld and the two-pass girth weld discussed in detail above. The wall thickness 


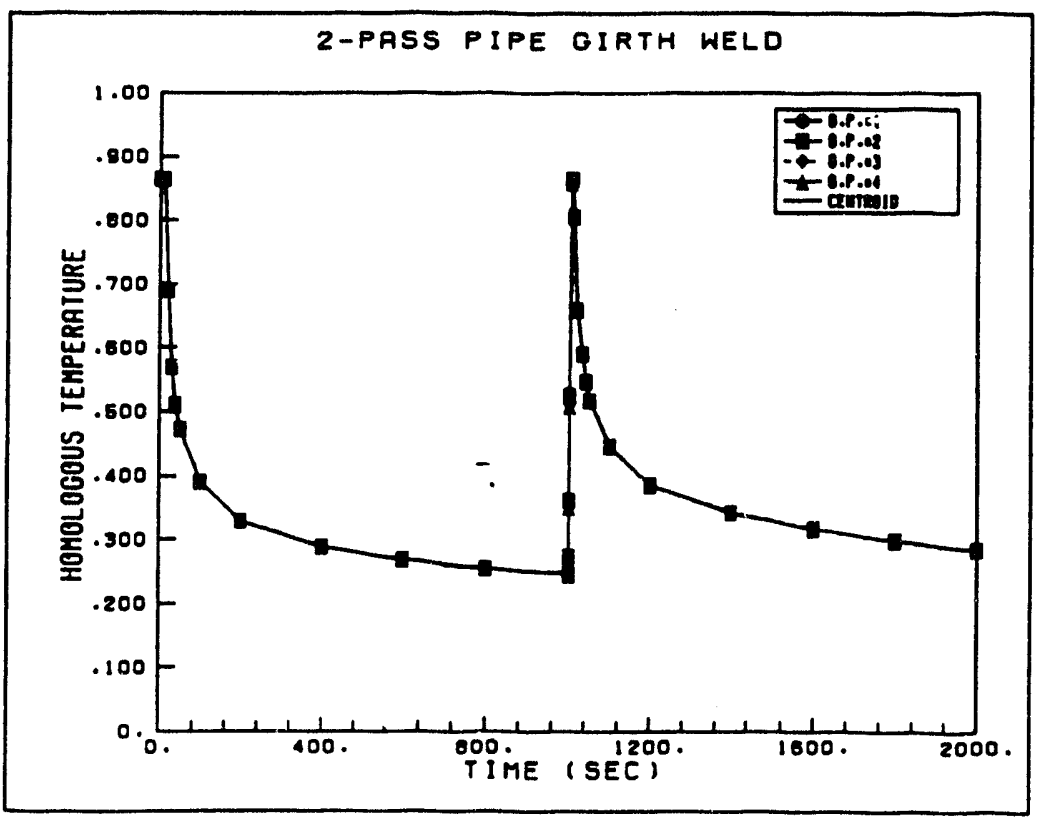

(a)

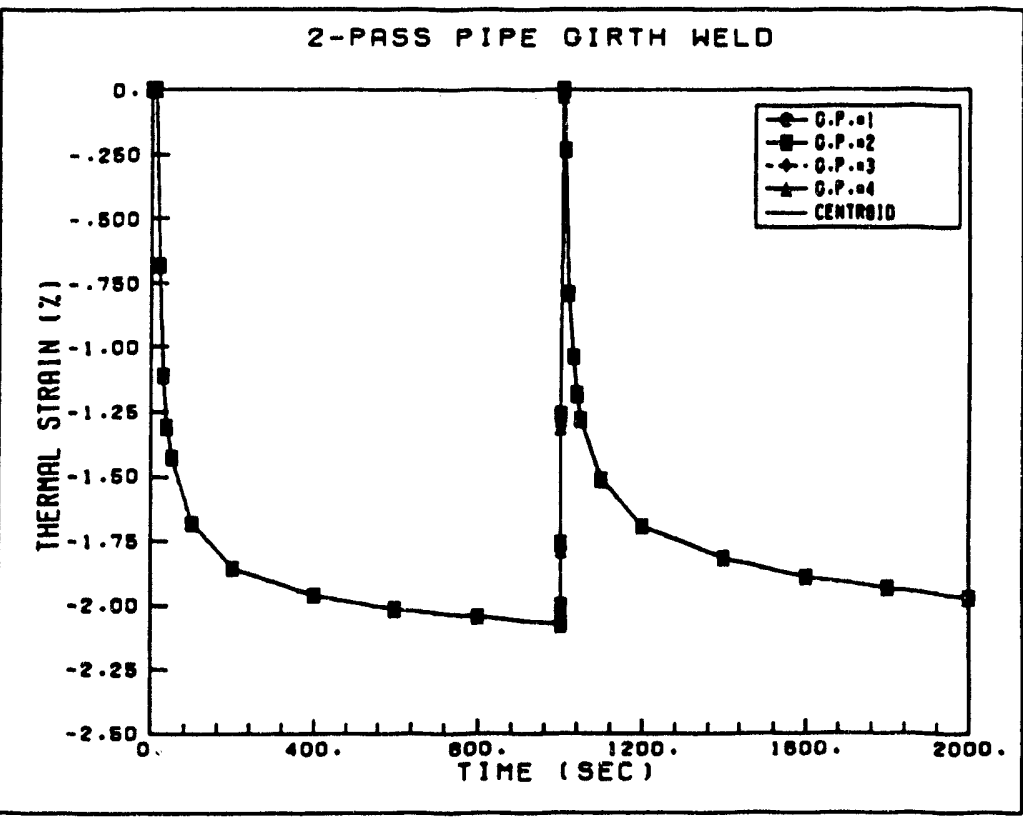

(b)

Fig. 4 (a)-(b). 


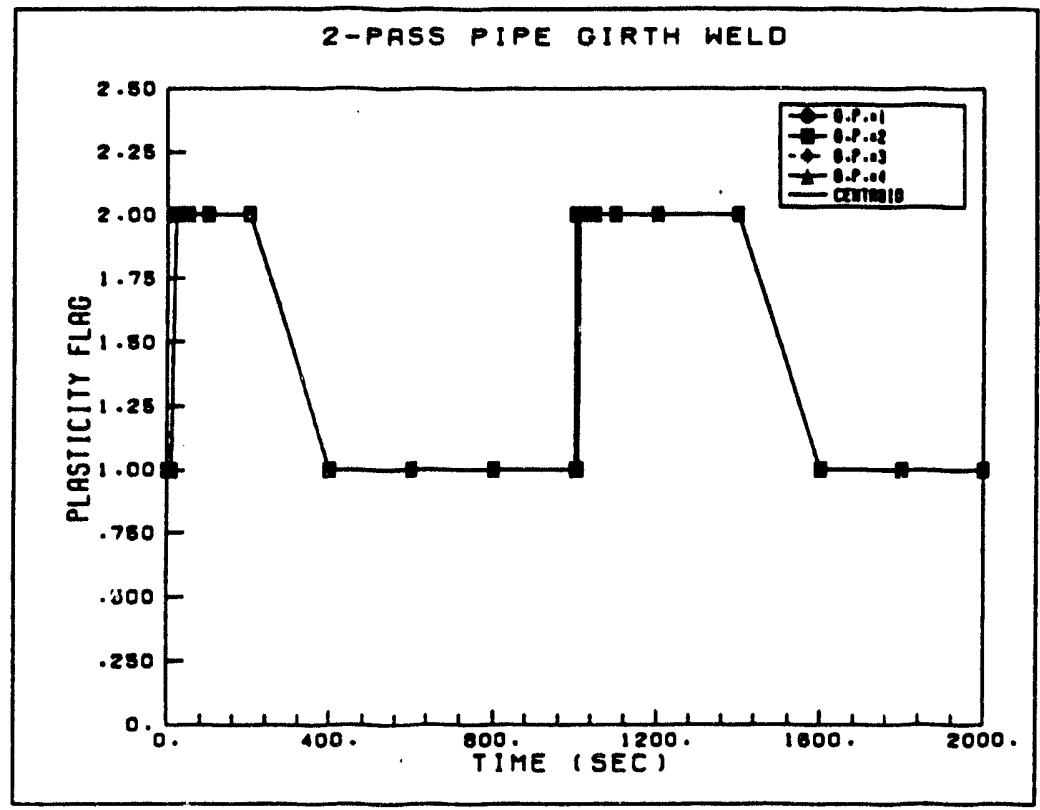

(c)

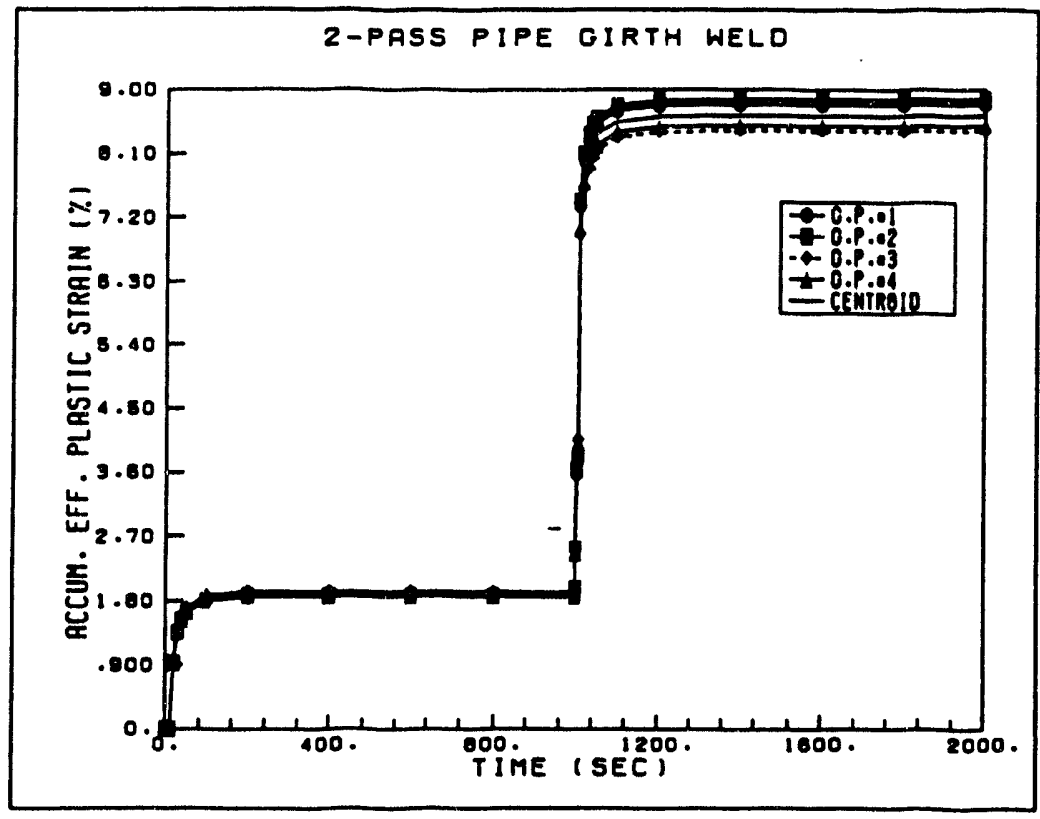

(d)

Fig. 4. Compuied welding history for the element at the center of the weld on the inner surface of a two-pass pipe girth weld: (a) temperature; (b) thermal strain; (c) plasticity flag; (d) accumulated effective plastic strain. 
(a)

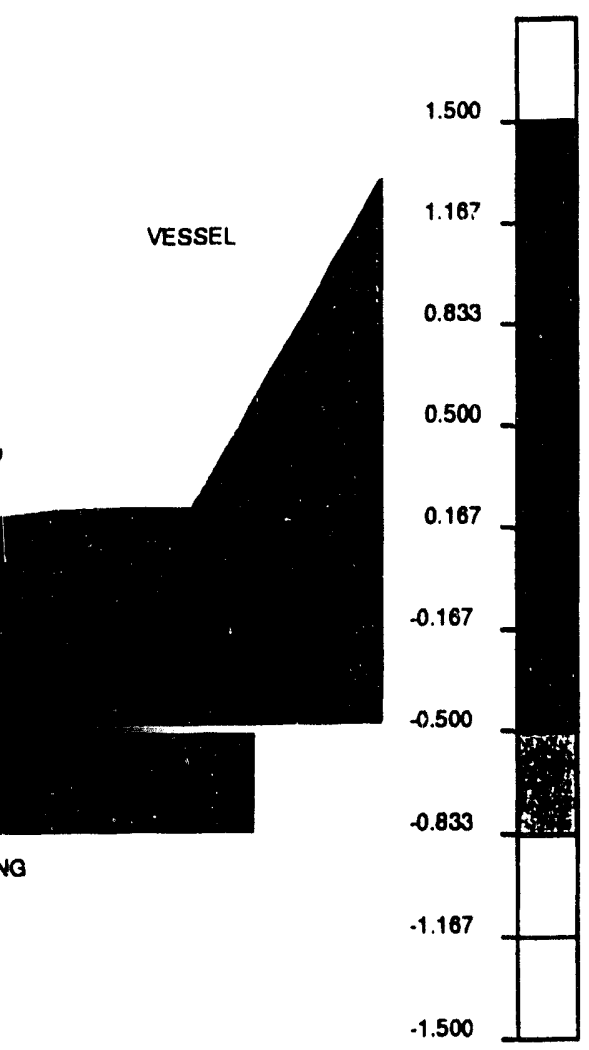

ADINA WELDNG ANALYSIS: ELEMENT CENTROID RESULTS

SXX SY, SZZ, SYZ,

(b)

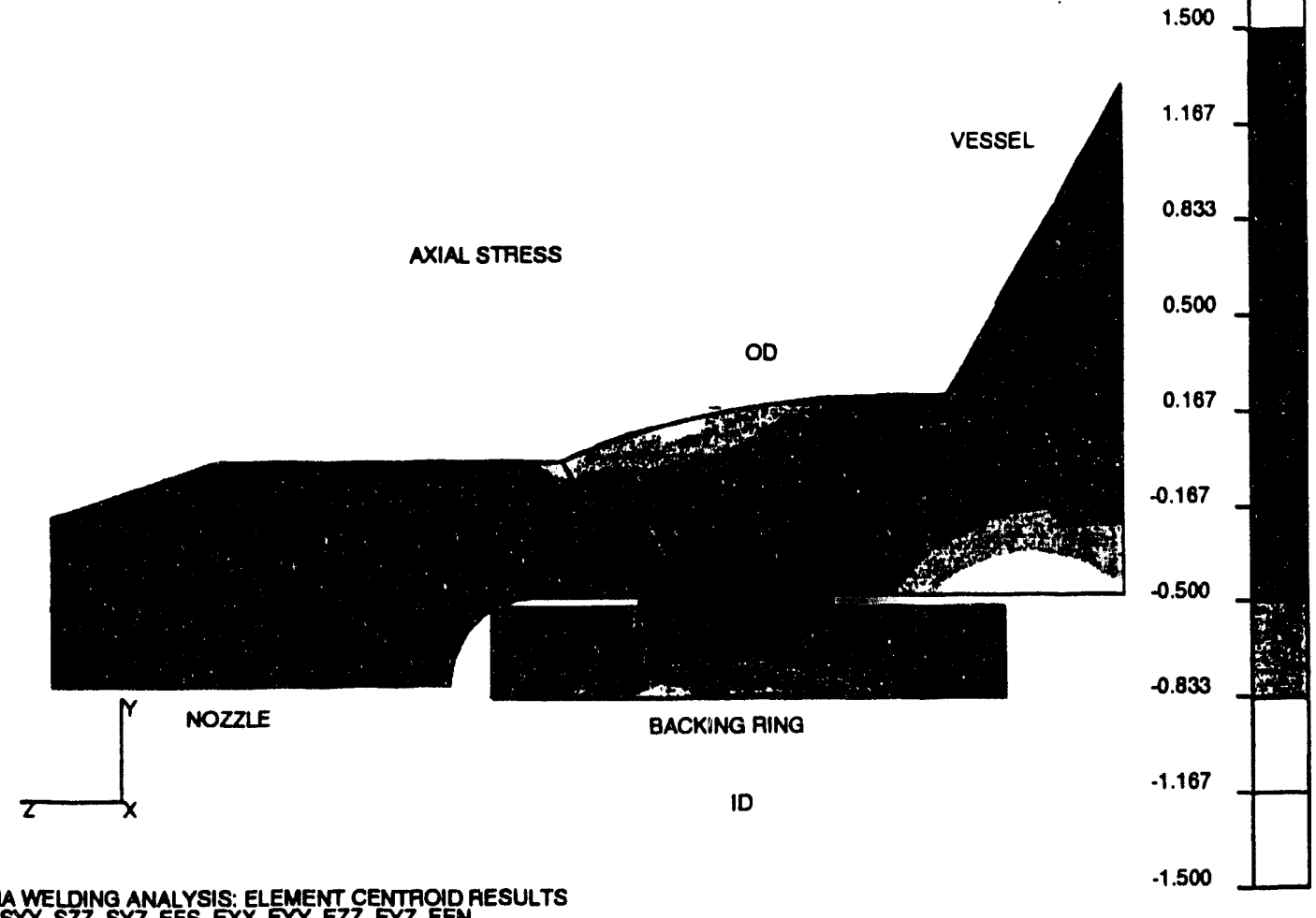

\section{ADINA WELDING ANALYSIS: ELEMENT CENTROOD AESULTS

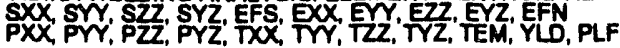

Fig. 5. Computed welding-induced residual stresses for a five-pass $(\sim 3$ layer) nozzle attachment weld (normalized by the room temperature yield strength of the weld metal): (a) hoop stress; (b) axial stress. 
of the nozzle is small enough that the weld behaves substantially like a thin-walled pipe girth weld, except for the obvious effects of the stress concentrations associated with the backing ring. The hoop and axial residual stresses are illustrated in Figs 5(a) and (b), respectively. Figure $5(b)$ illustrates the same type of axial bending stress distribution as the two-pass weld, aggravated at the ID by the stress concentrations located there. This analysis was used to achieve initial verification of WIRSAP against a WELD3 analysis performed by Rybicki [15]. The agreement between the WIRSAP and WELD3 results was excellent.

The two-pass girth weld results presented in Fig. 3, and the associated history plots presented in Fig. 4 are all based on the mixed variational formulation. From Fig. 4, especially, the excellent agreement between the four integration points is evident.

\section{Single-pass flat plate butt weld}

In this analysis, the through-thickness stress distribution in and near the weld was not sought. Rather, an in-plane 2D model was constructed for the purpose of studying the welding-induced in-plane displacements and the associated longitudinal and transverse stress state remote from the weld. The flat plate simulates, in two dimensions, a pipe girth weld that has been slit axially and flattened into a plane. Figure 6(a) illustrates the FE mesh for one-half of the flat plate.

SINGLE-PASS BUTT-WELDED FLAT PLATE

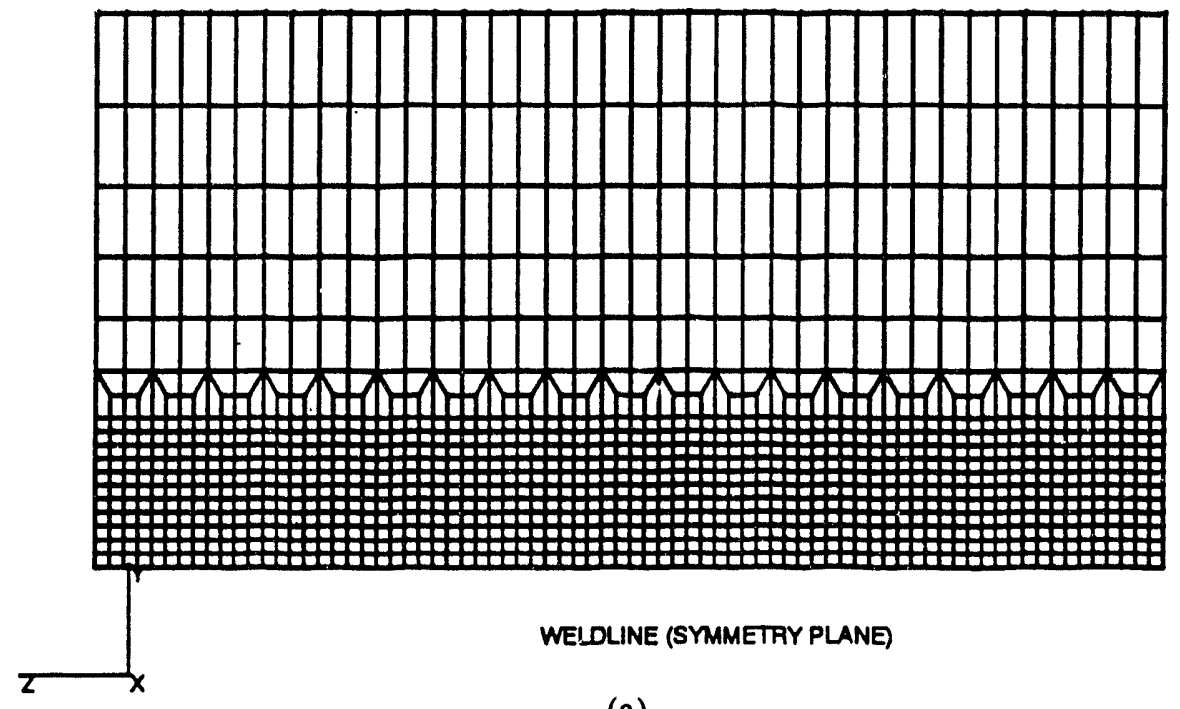

(a)

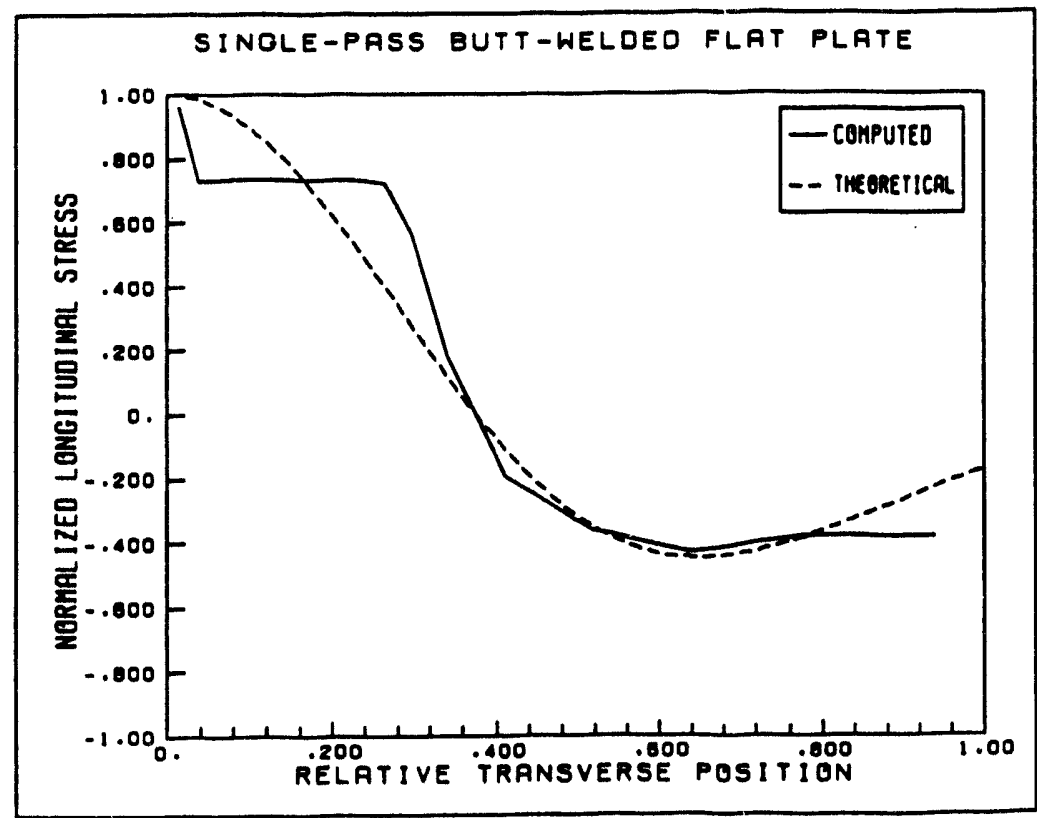

(b)

Fig. 6 (a)-(b). 


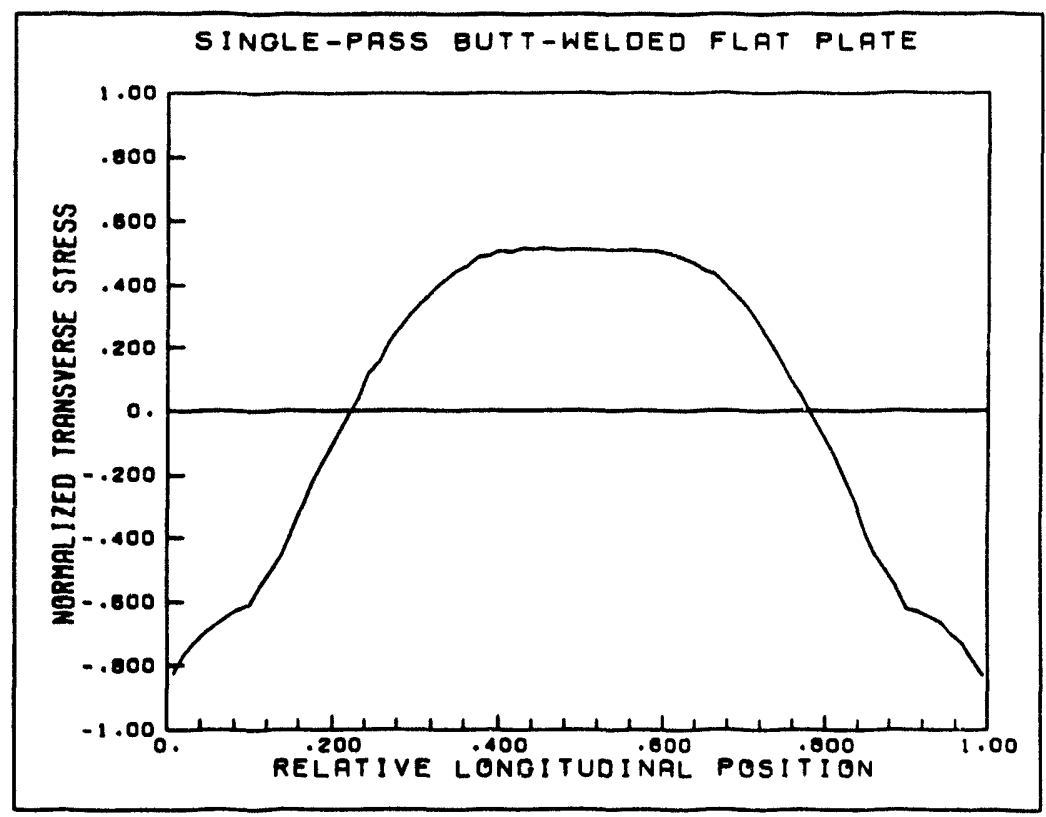

(c)

Fig. 6. WIRSAP results for a single-pass butt-welded flat plate (stresses have been normalized by the room temperature yield strength of the weld metal): (a) finite element mesh: (b) longitudinal stress variation across the center of the plate, compared to the analytical prediction from [16]; (c) transverse stress variation along the weld centerline.

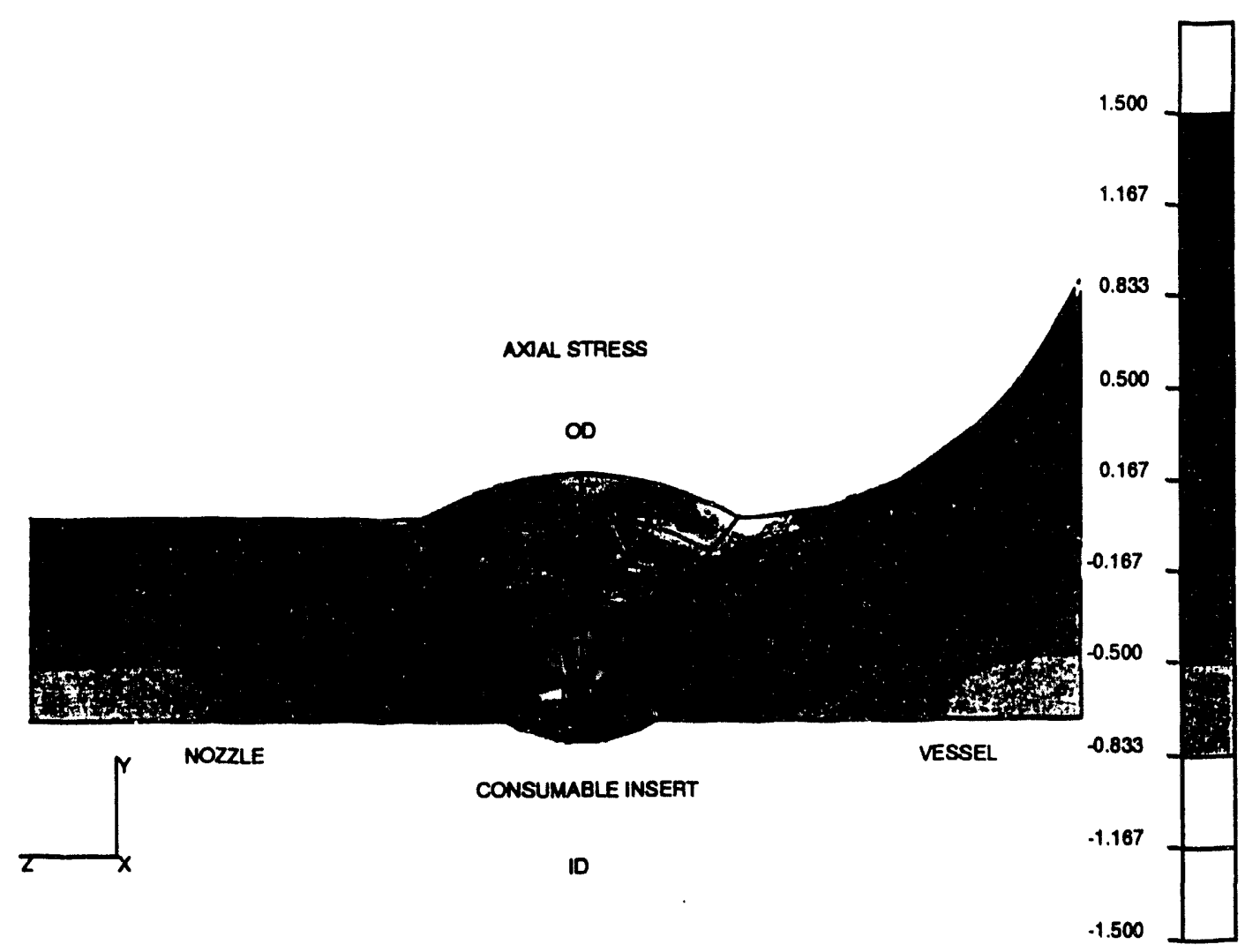

Fig. 7. Comparison of computed welding-induced residual axial stresses in a 16-pass (six-layer) consumable insert attachment weld design concept (normalized by the room temperature yield strength of the weld metal).

$-15-$ 
The longitudinal stress in the plate corresponds to the hoop stress in a pipe girth weld, while the transverse stress corresponds to the axial stress. This analysis was also a first step on the path toward 3D analysis, since it included the important modeling technique of sequentially moving the heat source (i.e., the welding torch) along the weld bead. This was accomplished by constructing a simple four-noded mesh with a string of 76 nominally square elements to represent the weld bead (actually half of its width, by symmetry). While there were some difficulties with achieving proper boundary conditions to simulate the tack welds at each end of the weld bead, the analysis was otherwise quite successful.

Each of the 76 weld elements has its own birth time, and the heat flow was achieved in a sequential element-by-element manner by utilizing a single triangular time function and an arrival time equal to the element birth time for each element. In this case, the heat input was modeled with internal heat generation, since there were no nodes internal to the weld bead elements. Even with this limiting level of coarseness in the mesh (i.e., only one element in the cross-section of the weld bead) the computed longitudinal stress at the center of the plate was in agreement with Masubachi's analytical prediction for a bead-on-plate geometry [16], as illustrated in Fig. 6(b). Also, the qualitative shape of the variation of the transverse stress along the weld bead, illus trated in Fig. 6(c), agrees with the predicted flat plate stress distribution (i.e., tension in the center, and compression on both ends of the plate.

Sixteen-pass nozzle attachment weld with consumable insert

This thicker-walled nozzle attachment weld apparently represents another step in complexity from the earlier two- and five-pass girth-like welds. Six layers of weld passes were involved in this weld, including the consumable insert. Although more remelting was involved, there was otherwise nothing substantially different about the method of analysis from the earlier girth-like welds. In fact, the results indicate that this attachment weld still behaved substantially like the thin-walled two-pass pipe girth weld, although the levels of axial stress on the ID surface in the weld and HAZ were somewhat lower. A gray-scale fringe plot of the axial stress component is illustrated in Fig. 7.

The 'blotchy' character of the fringe plot within the weld is indicative of the effects of 'volumetric locking', which is caused by the inability of the conventional displacement-based variational formulation of the four-noded quadrilateral element to model nearly incompressible deformation. Even after the double smoothing resulting from the averaging of the four integration point results and the nodal averaging

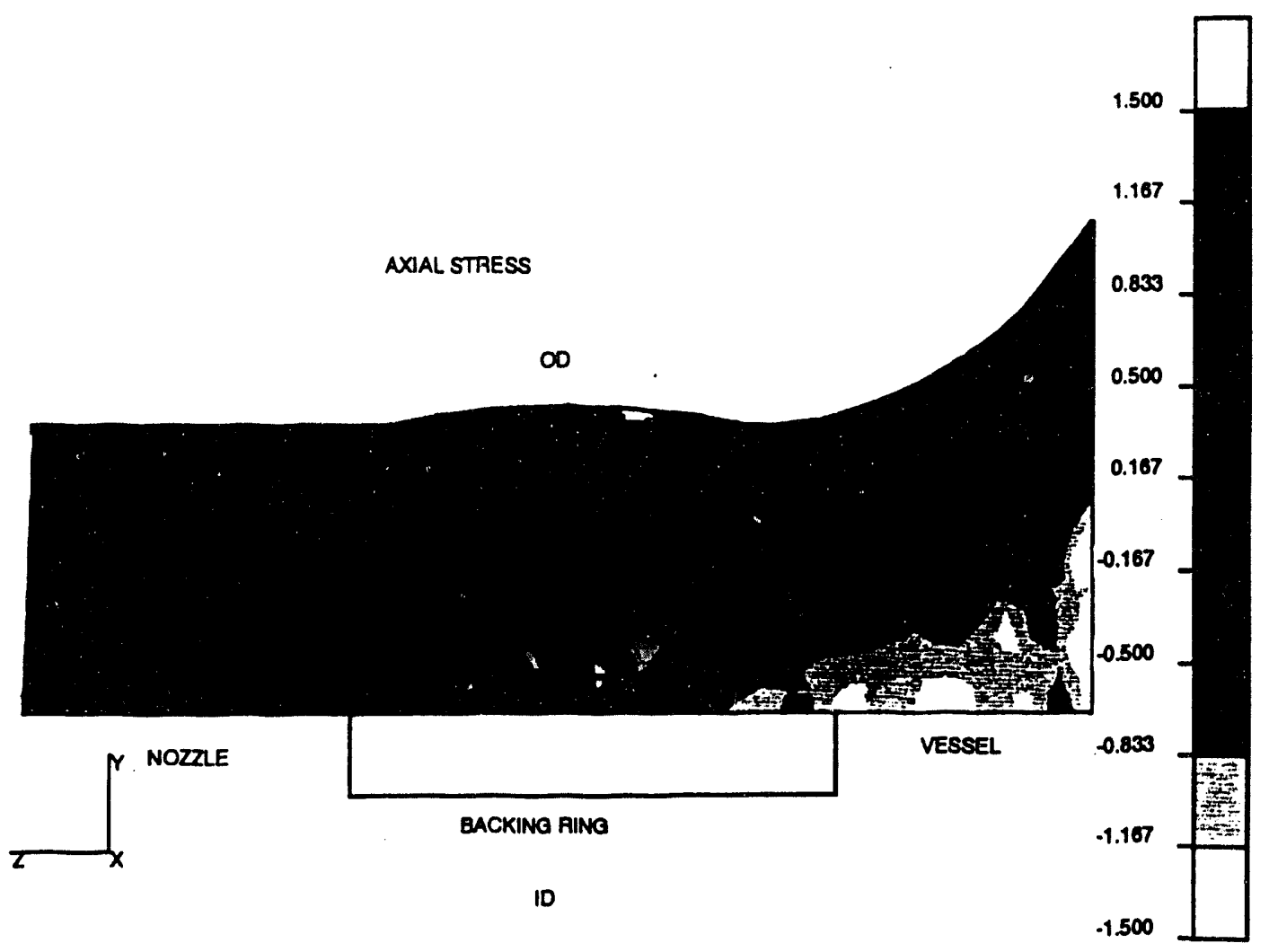

Fig. 8. Comparison of computed welding-induced residual axial stresses in a 23-pass (eight-layer) backing ring attachment weld design concept (normalized by the room temperature yield strength of the weld metal). 
performed by PATRAN when it computes nodal values from the element centroidal values, the residue of the 'checkerboard' variation of stresses is still apparent. A typical element within the weld bead might, for example, exhibit positive stresses on the order of several hundred $\mathrm{MPa}$ at two integration points on one element diagonal, while the two integration points on the other element diagonal exhibit negative stresses of nearly the same magnitude. On an element-to-eiement basis, a similar checkerboard-like oscillation was computed. When the source of this problem was discovered, the mixed variational (U/P) element formulation was used instead for all subsequent WIRSAP analyses.

The analysis of this design concept represents the first step in a hypothetical design optimization study, to investigate the use of WIRSAP as a comparative analytical tool to aid in the design of a SCC-resistant attachment weld.

Twenty-three-pass nozzle attachment weld with backing ring

A second attachment weld of the same nozzle was also considered. This design concept included a backing ring, like the five-pass attachment weld discussed earlier, but also included an even greater wall thickness, to potentially capitalize on the trend noted above and in [3] suggesting decreased axial stress on the ID surface with increasing pipe schedule (i.e., relative wall thickness). Eight layers of welding were involved. The hoop stress in this weld joint concept is still tensile through essentially the whole wall thickness, in the vicinity of the weld and HAZ, but Fig. 8 demonstrates that essentially no axial tension exists for this design concept, after removal (by machining) of the backing ring and the associated stress concentration region.

The effects of 'volumetric locking' are also evident in this figure, since this analysis was also performed with the displacement formulation. The five-pass attachment weld was also analyzed with the displacement formulation, but it exhibited 'volumetric locking' only to a minor extent. Apparently the problem is aggravated in multi-pass weld analyses.

Study of the history of the stress development in the manner discussed above for the two-pass pipe girth weld indicates that, in this thick-walled attachment weld, a different phenomenon occurs. After several layers of weld metal have been deposited (i.e., $\sim 3$ layers, or about $1 / 3$ of the wall thickness) the weldment is so stiff and strong that it (and the backing ring) effectively act like a mandrel-preventing radial and axial shrinkage. As each subsequent layer of weld metal is deposited, the axial shrinkage of the weld metal cannot be accommodated by radial motion. Instead, each increment of shrinking acts like a vise in the axial direction and exerts a clamping force on the previously deposited inner weld layers. As the last two (of eight total) layers are applied, the inner $\sim 1 / 3$ of the wall thickness is driven into axial compression by the 'compressive ratcheting' effect, channeled into the axial direction by the stiffness and strength of the inner weld layers. Virtually all the tensile axial stress on the ID is associated with the stress concentrations at the top and bottom of the backing ring. Much of the affected material is removed when the backing ring is machined away, but small regions of tension remain, as illustrated in Fig. 8.

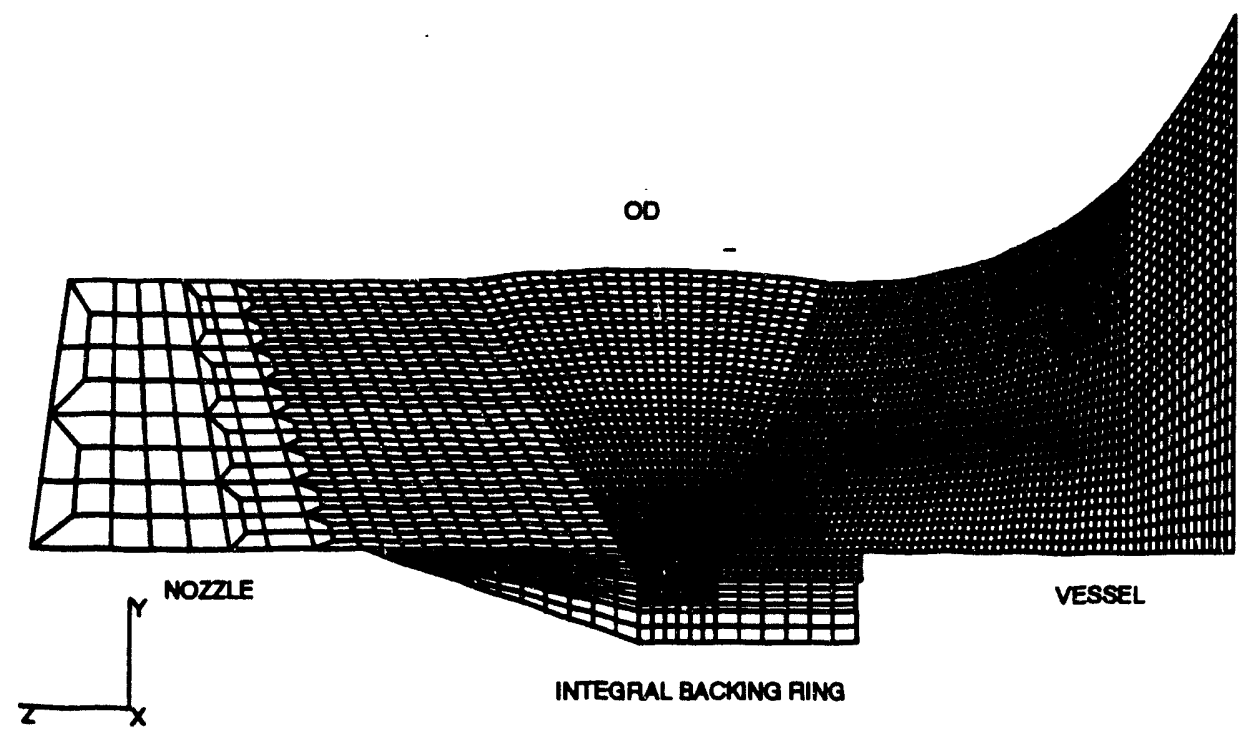

ID

Fig. 9. Finite element mesh, in the vicinity of the attachment weld, for the 25-pass (nine-layer) thick-walled nozzle attachment weld design concept, with an integral backing ring. 


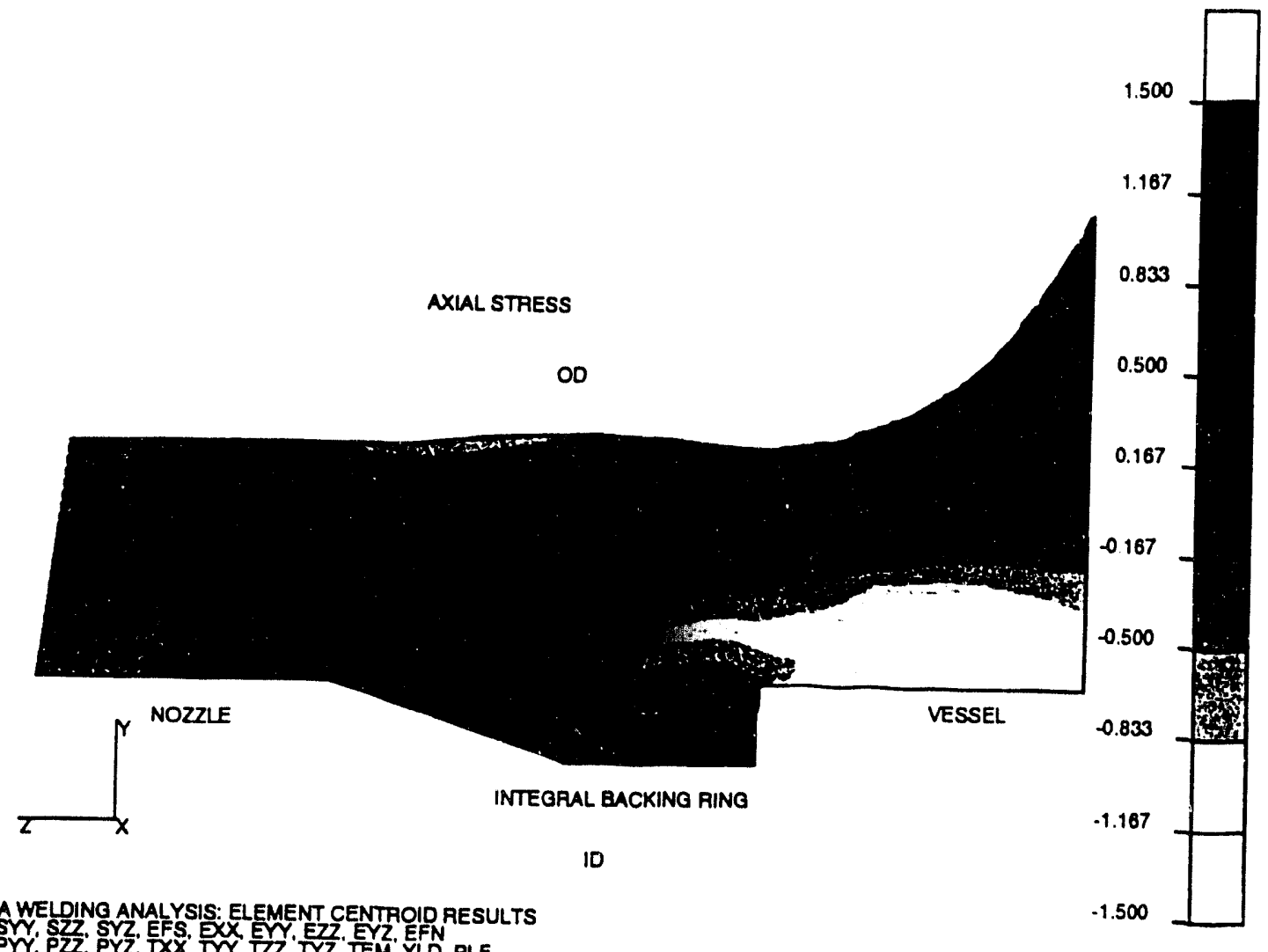

ADINA WELDING ANALYSIS: ELEMENT CENTROID RESULTS

Fig. 10. Computed welding-induced residual axial stress in a 25 -pass (nine-layer) thick-walled nozzle attachment weld design concept, with an integral backing ring (normalized by the room temperature yield strength of the weld metal), upon completion of welding. and prior to removal of the integral backing ring.

Twenty-fice-pass no:zle attachment weld with integral backing ring

Continuing this hypothetic design optimization process, another weld design concept was considered, in an attempt to combine the best features of the two preceding concepts: the thick-walled behavior of the 23-pass backing-ring design concept, and an approximation to the non-stress-concentrating consumable insert geometry. The integral backing ring, which is removed by machining after the weld is completed, has a stress concentration on one side of the weld gap only. An additional weld layer is also associated with the integral backing ring. The excess material on the ID surface is machined off after the welding is completed. This will, presumably, act to remove the tensile axial stresses caused mainly by the stress concentration associated with the gap at the bottom end of the backing ring and will leave behind only the favorable compressive stress state produced naturally by the 'compressive ratcheting' effect acting in conjunction with the enhanced axial and hoop stiffness of the greater wall thickness of this design concept.

Details of the finite element mesh in the vicinity of the attachment weld are illustrated in Fig. 9, while Fig. 10 illustrates the axial residual stress for this design concept, prior to removal of the integral backing ring. The effect of the stress concentration due to the backing ring is clearly evident. After removal of the backing ring and the associated excess material on the bore ID, the final residual stress state shown in Fig. 11 remains. From these figures, it is seen that the thick-walled, integral backing design concept does, in fact, achieve the desired design goal of producing compressive axial stresses on the ID surface of the weldment, throughout the weld and both HAZs. Figures 10 and 11 also demonstrate the effectiveness of the mixed pressure/displacement (U/P) element formulation in eliminating the 'blotchy' checkerboard behavior of the stress results (contrast these figures with Figs 7 and 8, for example).

A pair of stainless steel mock-ups of this design concept were prepared for the purpose of providing residual stress data for use in qualifying the $2 D$ version of WIRSAP. The mock-ups were prepared with a special welding procedure, in which the sequence, location, and extent of each circumferential sector of weld bead in each pass was varied as necessary to keep the nozzle centerline accurately aligned with the bore centerline at all times. It was anticipated that this welding procedure would result in a nearly axisymmetric residual stress state. 


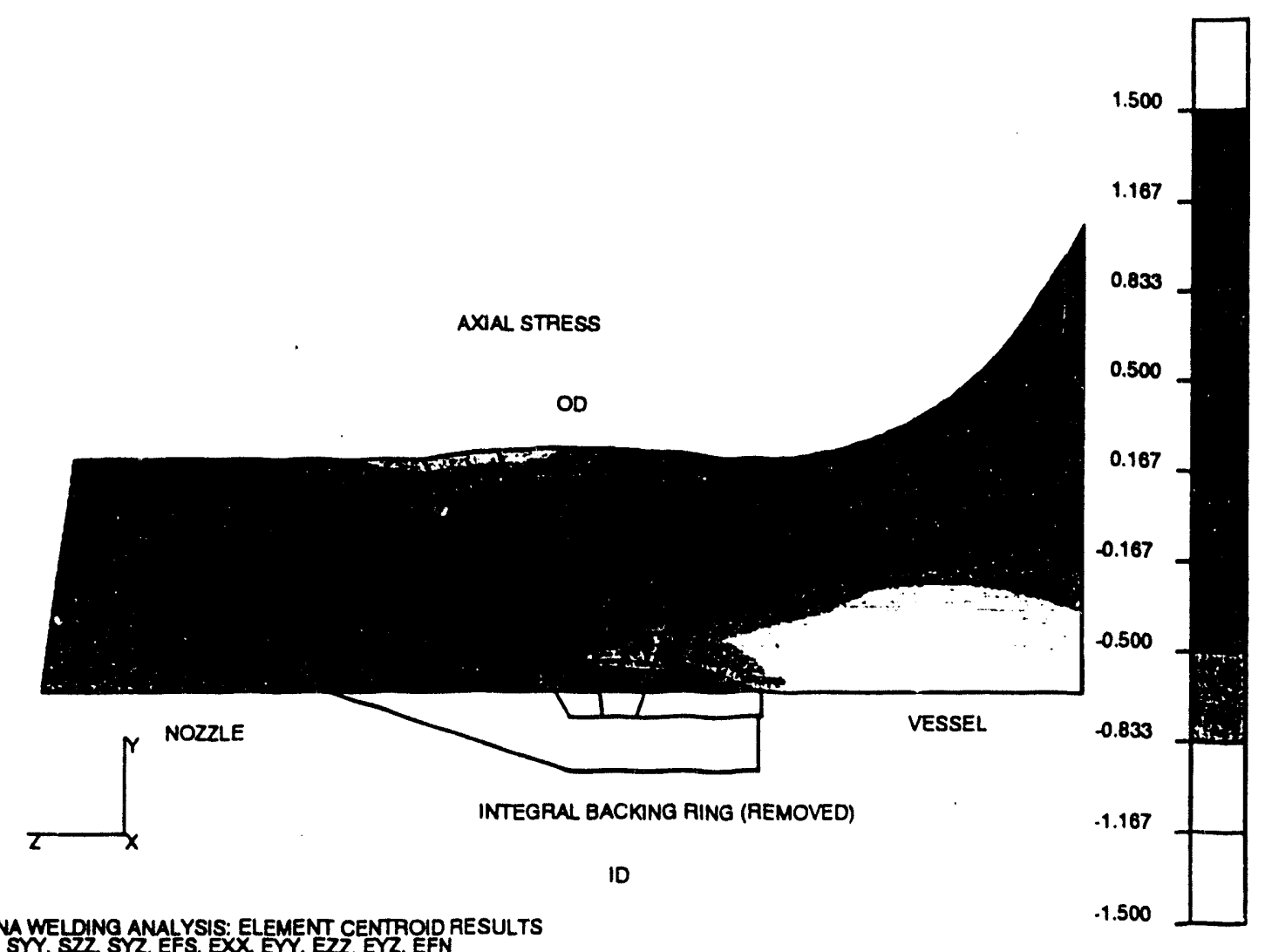

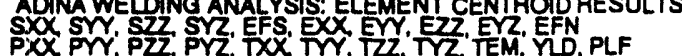

Fig. 11. Computed welding-induced residual axial stress in a 25-pass (nine-layer) thick-walled nozzle attachment weid design concept, with an integral backing ring (normalized by the room temperature yield strength of the weld metal), after removal of the integral backing ring.

One of the mock-ups was subjected to a 24-hour exposure in boiling $\mathrm{MgCl}_{2}$, which is an aggressive SCC environment sufficient to produce cracking for tensile stress levels above about $70 \mathrm{MPa}(10 \mathrm{ksi})$ [17]. The observation that no cracking occurred-either circumferential or axial-demonstrates that only very low tensile stresses (or compressive stresses) exist on the ID surface in either the hoop or axial directions. The observation also supports the hypothesis that the residual stress state is nearly axisymmetric (although it is not sufficient to prove it). Welding-induced residual stress measurements will be performed on the second mockup in the near future, to complete the intended qualification function.

\section{CONCLUSIONS}

Consideration of this hypothetic weld joint design optimization process demonstrates what is perhaps the most powerful potential use of a WIRSAP welding simulation analysis-the comparison and ranking of two (or more) conceptual designs, for the purpose of selecting the weld joint design that minimizes the potential for SCC failure by minimizing the tensile stress level on the wetted surface. It is not always necessary that absolute accuracy be achieved in the estimation of the magnitude of the welding-induced residual stresses. It may be enough to accurately estimate the qualitative nature of the residual stress state. This work has demonstrated that such an objective can be readily achieved (albeit with the expenditure of a sizeable amount of CPU time) with the computational power of the ADINA software system and a few special-purpose pieces of auxiliary software. While the cost of these analyses is significant, the cost of manufacturing and testing several mock-ups of each of the intermediate conceptual attachment weld designs may be much greater.

\section{REFERENCES}

1. E. F. Rybicki, D. W. Schmueser, R. W. Stonesifer, J. J. Groom and H.W. Mishler, A finite-element model for residual stresses and deflections in girth-butt welded pipes. ASME J. Pressure Vessel Technol. 100, 256-262 (1978).

2. E. F. Rybicki and R. B. Stonesifer, Computation of residual stresses due to multipass welds in piping systems. ASME '. Pressure Vessel Technol. 101, 149-154 (1979).

3. E. F. Rybicki, P. A. McGuire, E. Merrick and J. Wert, The effect of pipe thickness on residual stresses due to girth welds. ASME J. Pressure Vessel Technol. 104 204-209 (1982).

4. L. Josefson, M. Jonsson, L. Karisson, R. Karisson, T. Karlsson and $L$. Lindgren, Transient and residual stresses in a single-pass butt welded pipe. In Inter national Conference of Residual Stresses, ICRS2 (Edited 
by G. Beck, S. Denis and A. Simon), pp. 497-503. Elsevier, New York (1989).

S. C. T. Karlsson, Finite element analysis of temperatures and stresses in single-pass butt-welded pipeinfluence of mesh density and material modelling. Engng Computations 6, 133-141 (1989).

6. R. I. Karlsson and B. L. Josefson, Three-dimensional finite element analysis of temperatures and stresses in a single-pass butt-welded pipe. ASME J. Pressure Vessel Technol. 112, 76-84 (1990).

7. E. Friedman, Thermomechanical analysis of the welding process using the finite element method. ASME J. Pressure Vessel Technol. 97, 206-213 (1975).

8. J. A. Goldak, A. P. Chakravarti and M. J. Bibby, A new finite elemeat model for welding heat sources. Metall. Trans. B 15B, 299-305 (1984).

9. J. A. Goldak, M. J. Bibby, J. E. Moore, R. House and B. Patel, Computer modeling of heat flow in welds. Metall. Trans. B 17B, 587-600 (1986).

10. C. K. Leung, R. J. Pick and D. H. B. Mok, Finite element modeling of a single pass weld. Welding Research Council Bulletin 356, pp. 1-10 (1990).
II. D. K. Leung and R. J. Pick, Finite element analysis of multi-pass welds. Welding Research Council Bulletin 356, pp. 11-33 (1990).

12. R. J. Dexter, S. C. Grigory and W. R. Schick, Residual stress and deformation prediction in welded structural components. SwRI Internal Research Project 06-9497. final report (1987).

13. R. J. Dexter and D. Pont, Residual stress analysis in reactor pressure vessel attachments: review of available welding simulation software. EPRI NP.7469, Project C102-3, interim report (1991).

14. V. J. Papazoglou and K. Masubuchi, Numerical analysis of thermal stresses during welding including phase transformation effects. ASME J. Pressure Vessel Technol. 104, 198-203 (1982).

15. E.F. Rybicki, Private communication.

16. K. Masubuchi, Analysis of Welded Siruciures, pp. 191193. Pergamon Press, Oxford (1980).

17. E. E. Denhard, Effect of composition and heat treatment on the stress corrosion cracking of austenitic stainless steels. Corrosion 16, 131-141 (1990). 

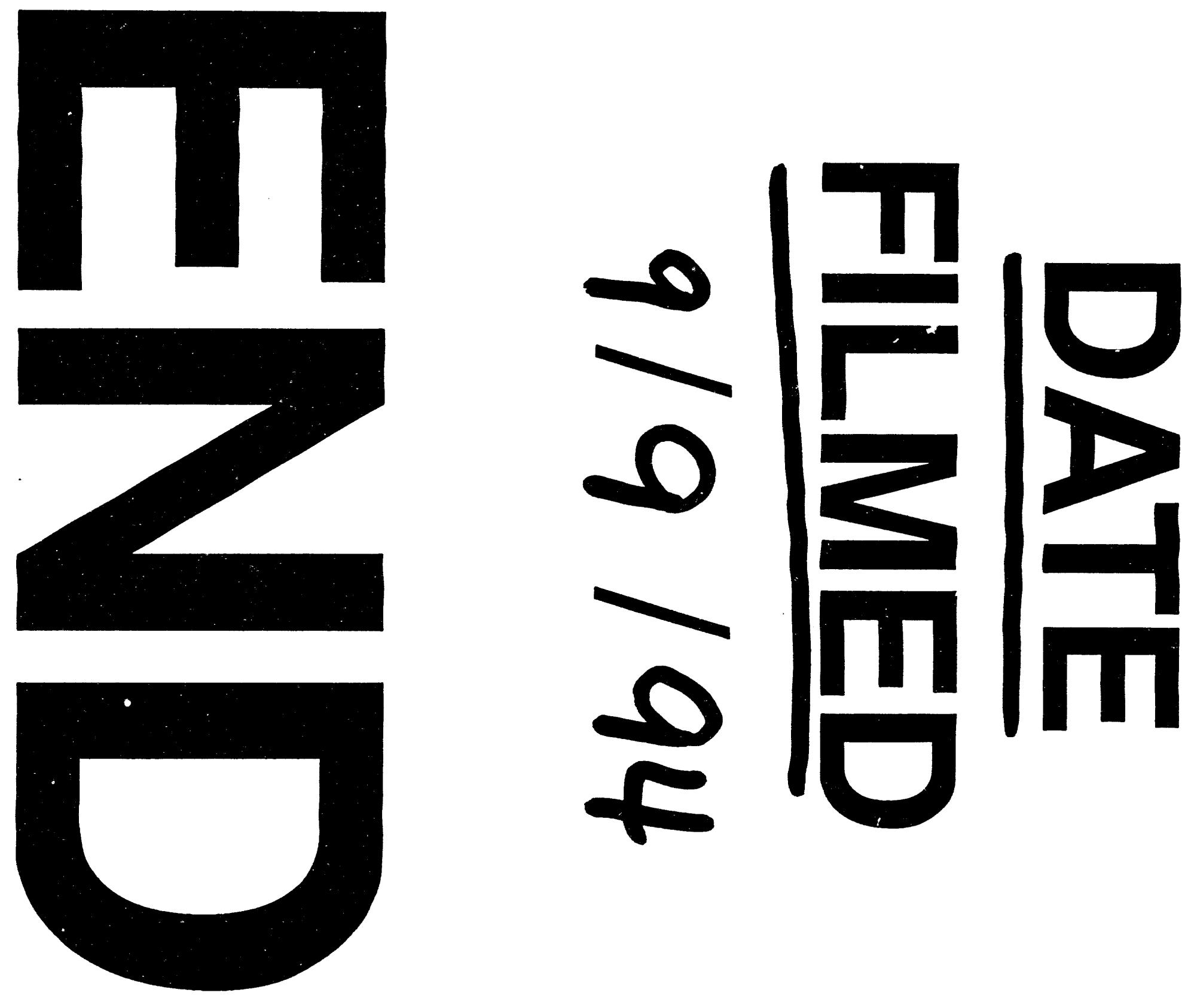